\title{
TU/e EnNHONEN

\section{Two-way coupled CFD fire and thermomechanical FE analyses of a self-supporting sandwich panel façade system}

\section{Citation for published version (APA):}

de Boer, J. G. G. M., Hofmeyer, H., Maljaars, J., \& van Herpen, R. (2019). Two-way coupled CFD fire and thermomechanical FE analyses of a self-supporting sandwich panel façade system. Fire Safety Journal, 105, 154-168. https://doi.org/10.1016/j.firesaf.2019.02.011

DOI:

10.1016/j.firesaf.2019.02.011

Document status and date:

Published: 01/04/2019

\section{Document Version:}

Accepted manuscript including changes made at the peer-review stage

\section{Please check the document version of this publication:}

- A submitted manuscript is the version of the article upon submission and before peer-review. There can be important differences between the submitted version and the official published version of record. People interested in the research are advised to contact the author for the final version of the publication, or visit the $\mathrm{DOI}$ to the publisher's website.

- The final author version and the galley proof are versions of the publication after peer review.

- The final published version features the final layout of the paper including the volume, issue and page numbers.

Link to publication

\section{General rights}

Copyright and moral rights for the publications made accessible in the public portal are retained by the authors and/or other copyright owners and it is a condition of accessing publications that users recognise and abide by the legal requirements associated with these rights.

- Users may download and print one copy of any publication from the public portal for the purpose of private study or research.

- You may not further distribute the material or use it for any profit-making activity or commercial gain

- You may freely distribute the URL identifying the publication in the public portal.

If the publication is distributed under the terms of Article 25fa of the Dutch Copyright Act, indicated by the "Taverne" license above, please follow below link for the End User Agreement:

www.tue.nl/taverne

Take down policy

If you believe that this document breaches copyright please contact us at:

openaccess@tue.nl

providing details and we will investigate your claim. 
J.G.G.M. de Boer ${ }^{a}$, H. Hofmeyer ${ }^{a}$, J. Maljaars ${ }^{a, b}$, R.A.P. van Herpen ${ }^{a, c}$

${ }^{a}$ Eindhoven University of Technology, Eindhoven, The Netherlands

${ }^{\mathrm{b}} \mathrm{TNO}$, The Hague, The Netherlands

${ }^{c}$ Nieman Consulting Engineers, Zwolle, The Netherlands

\section{Abstract}

A self-supporting sandwich panel façade system under fire is studied. First, a thermomechanical FE model, which comprises the complete façade system, and incorporates material degradation and geometrical nonlinear behaviour except for the insulation material and connections, is loaded by a fire temperature curve. Eurocode design rules then predict the screw connections of a sandwich panel will fail in shear. Secondly, an existing programme, FDS-2-Abaqus, is extended to allow its two-way coupled analyses, in which CFD fire simulations are updated for changes in the thermomechanical FE model, to be applicable to the façade system. Again, these simulations show the shear failure of the screws. Parameter studies show differences in system behaviour for improved screw properties; a fuelcontrolled vs. ventilation-controlled fire; and different panel thicknesses. Interestingly, as thermal bowing of the panel retards screw failure, and thicker sandwich panels bow less than thinner panels, thicker façade panels will decrease failure time. This and other insights obtained, and the predicted failure of two tiny but critical screws within 80 seconds, as compared to 150 minute lasting sandwich panels in standard fire tests, stresses the need to study complete systems under realistic fires, rather than to study individual components in standard fire tests. Future research will focus on detailed FE models of the connections; full-scale fire experiments; CFD temperature measurement points at the façade outside; detailed modelling of the insulation; and the effects of high temperature creep.

\section{Keywords}

Fire Safety Engineering; two-way coupled CFD-FEM analysis; façade system; FDS-2-Abaqus

\section{Introduction}

Fire Safety Engineering is of crucial importance for the safety of building occupants, to escape a building in timely fashion in case of fire, and to ensure the structure system retains its structural strength and stability until everyone is safe (Zhang et al., 2016). Its importance was further stressed after the collapse of the World Trade Centre (WTC) Towers in 2001 (Baum, 2011; Prasad \& Baum, 2005). It became clear that there was a lack of knowledge on how to accurately simulate complex fire behaviour, and how to transfer this behaviour towards Finite Element Method (FEM) models to predict the response of the structure system (Duthinh et al., 2008). This led to a recommendation from the American National Construction Safety Team (NCST) to promote software to study realistic fire behaviour, to assist in the design of new fire protection systems, and to analyse buildings exposed to fire (NIST, 2005).

Structure systems are engineered following (international) design standards, and the same applies to the prediction of the strength and stiffness of structural elements under fire. For such predictions, the behaviour of the fire is often simplified and e.g. the standard ISO-834 fire curve can be used to describe the gas temperature around a structure over a given period (EN 1991-1-2, 2002; ISO 834-1, 1999). The subsequent structure's temperature, strength, stiffness, and period of time of fire resistance can then be found by design rules as found in e.g. the Eurocode (EN 1993-1-2, 2005) for steel structures. For the nominal (standard) fire case, the elements of the structure system, e.g. a column, will be checked to meet a specific period of fire resistance by means of the theoretically and numerically based design rules and furnace tests. The advantage of this approach is the relatively simple procedure, the fact that design standards are used globally, and, most importantly, have proven to be safe.

However, this approach does not fully take into account the behaviour of the overall system, including connections, second order effects, large displacements and material nonlinearities. Moreover, the temperature-time curve (ISO$834,1999)$ may not accurately represent a realistic fire development, and equally important, it does not account for the fire distribution within the fire compartment (Silva et al., 2016). Another aspect is the safety of fire fighters, 
rescue workers, and caregivers, who will work in or around the building at a stage where design rules no longer apply. To guarantee their safety, more information on smoke production and the overall structural response should be known in this later stage (Andreozzi et al., 2014).

Finally, research and design codes have focussed on the degradation of material properties, with the structural behaviour of the elements considered similarly to the situation at an ambient temperature but including reduced stiffness and strength. This may be a valid approach for statically determinate structures; however, it does not accurately describe the behaviour of indeterminate structures due to missing restraints and thermal expansion (Wang et al., 1995). Also, later studies provide additional proof that the thermal behaviour and expansion of a structure system should be taken into account (Kirby, 1997; Sanad et al., 2000). Actually, after the famous Cardington tests, comprising a full-scale fire test of an eight-storey composite steel frame structure system, Usmani et al. (2001) demonstrated that thermally induced forces and displacements have an even larger impact on the structural response than material degradation.

To improve on the above-mentioned challenges, current research includes the application of Computational Fluid Dynamics (CFD) to model a fire and the Finite Element Method (FEM) to simulate the thermomechanical behaviour of a structure. These two techniques are coupled either one-way or two-way, as will be explained further in the following sections, introduced by relevant experimental research.

\subsection{Experiments}

Related to the research presented in this paper, full-scale and intermediate or small-scale experiments can be distinguished. Full-scale experiments mainly focus on the behaviour of the structure system: Pyl et al. (2012) constructed a full size, steel frame, industrial building for a fire experiment. The building's cladding consisted of stone wool sandwich panels, whereas the roof was made of PIR sandwich panels. Wood cribs were used as fuel. The experiment lasted 62 minutes, which was in good agreement with the simulations that predicted 27 min for a standard fire and $54 \mathrm{~min}$ for a natural fire. Pyl et al. also confirmed that the "Results of full-scale tests on 3D coldformed frame structures are not or hardly available". Lou et al. (2018) tested the behaviour of a $12 \times 6 \mathrm{~m}$ steel portal frame exposed to fire from a $4 \times 6 \mathrm{~m}$ compartment, with the frame collapsing after 20 minutes of heating with a column temperature equal to $850{ }^{\circ} \mathrm{C}$. It was found that standard fire models underestimate the fire, whereas parametric fire models are only realistic if delayed in time. Since full-scale experiments are very expensive, and due to their nature may lack detailed data, most research still focuses on intermediate or small-scale experiments: Kolarkar (2010) designed a gas furnace to measure the time vs. temperature and load vs. deformation characteristics of a complete steel stud wall system. Other research tested a bare steel beam under a localized fire, to tune a simulation model to replace the prescriptive methods found in the current fire codes (Zhang et al., 2018). The same group also reported on an experiment in which a 6 metre long steel W-beam was subjected to a localized fire, in order to improve the development of realistic and controlled fire tests (Zhang et al., 2017). Buckling of thin-walled structures under elevated temperatures was investigated with, among others, experiments on aluminium box and angle sections (Maljaars et al., 2009). EN 1364-1:2014 prescribes the test to determine the fire resistance of nonload-bearing walls, which also applies to the façades discussed here, as long as they are not curtain walls. Following such a test, EN 1363-1 is used to determine the resistance in terms of so-called El levels. Many related test reports can be found in the literature. Wang and Foster (2017) present experiments on sandwich panels with PIR insulation, to obtain a temperature dependent thermal conductivity for PIR, and to focus on behaviour of the tongue and groove connections. Although this paper focuses on the fire resistance of façades to an interior fire, a lot of research focuses on fire spread in façades. The unfortunate 2017 Grenfell Tower fire once again stressed the importance of this research. Namely, either an externally or internally started fire can spread via openings and corners in the façade itself, especially if larger vertical cavities are present. As such, the fire moves rapidly to other parts of the building, a process that will be helped further if the façade structure contains combustible materials. An overview of related accidents and test protocols can be found in e.g. White \& Delichatsios (2015) and Wade \& Clampett (2000), and related (full-scale) tests can be found in e.g. Weghorst et al. (2016) and Guillaume et al. (2018) in Figure 1.

\subsection{One-way coupled CFD-FEM}

In an analysis using one-way coupled CFD-FEM, the result of a fire simulation, via CFD software, will be coupled to a thermomechanical analysis by FEM software. In the thermomechanical analysis, first a heat transfer analysis is carried out using the temperatures of the fire simulation. Subsequently, the results of the heat transfer analysis will 
be coupled to a structural response analysis. This method is able to provide reliable fire safety engineering analyses (Banerjee et al., 2009; Prasad \& Baum, 2005; Silva et al., 2014, 2016). However, the challenges that are found in the underlying differences with respect to algorithms, discretization, and time scales between CFD and FEM models, means the development of a coupled CFD-FEM approach is not a trivial task. For example, FEM convergence is sometimes problematic; however, it can be improved by averaging the time in the transfer of CFD data to an FEM model (Yu \& Jeffers, 2013). Another difficulty concerns the differences in mesh size and node location between the CFD and FEM models. Beata \& Jeffers (2015) solved this problem by developing a trapezoid rule algorithm, based on averaging, sampling, and least squares, to overcome these differences.

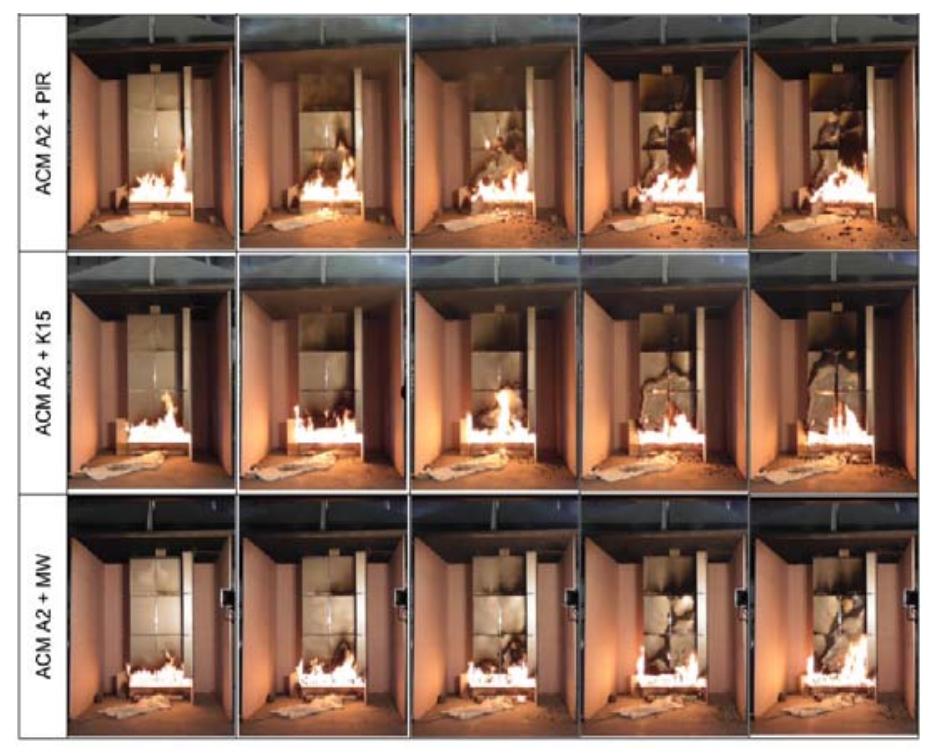

Figure 1- Fire spread experiments on façade systems consisting of limited-combustibility cladding (ACM A2) and insulation by PIR, phenolic foam (K15), and mineral wool (MW), Guillaume et al. (2018).

A commonly used CFD software programme for fire is Fire Dynamics Simulator (FDS), which has been validated to achieve reliable heat parameters and to simulate a fire accurately (McGrattan et al., 2013; Ryder et al., 2004). With respect to thermomechanical FEM simulations, Maljaars et al. (2009a, 2009b) successfully verified these simulations in their study with experiments for a column exposed to fire. Because of the promising results for both CFD and FEM simulations, and the fact that real fire experiments of complete systems are complex, expensive, and timeconsuming, several studies have researched a coupled CFD-FEM approach, e.g. Ren et al. (2007) and Franssen (2005). In every case, in-house code was developed, which transferred the results of the fire simulations to the structural simulations.

The introduction of the Adiabatic Surface Temperature (AST) has shown a very efficient way of transferring information between the CFD and FEM models (Wickström et al., 2007) and has proved to be an adequate method for the temperature transfer between these models (Andreozzi et al., 2014). The AST is easy to calculate and ensures that the thermal and structural model can operate without any major modifications (Wickström et al., 2007). It can be obtained by the fire model but can also be measured by plate thermometers (PT) in real fire experiments, as specified in the international fire resistance test standard ISO-834 (ISO 834-1, 1999).

Finally, several research projects have been carried out in which the quality of coupled CFD-FEM analyses was validated by real fire experiments (Alos-Moya et al., 2014; Gunalan \& Mahendran, 2013; Silva et al., 2014, 2016; Tondini et al., 2012; Zhang et al., 2016).

\subsection{Two-way coupled CFD-FEM}

The studies described so far focused on the coupling of data from the CFD fire simulation to the FEM model. However, research has also started to focus on two-way coupled simulations, which additionally transfer the structural response of the thermomechanical FEM simulations back to the fire model (Chen et al., 2011; Luo et al., 2010). 
In specific cases, two-way coupled CFD-FEM analyses provide a more reliable analysis than one-way coupled CFDFEM analyses. For example, if a façade exposed to fire is considered, due to large displacements and thermal stresses parts may fail, which will lead to changing boundary conditions for other parts of the structure. Also, an opening in the façade may occur, which will affect the behaviour of the fire. For these and other reasons, it would be more reliable and realistic to couple the changes in boundary conditions and geometry back to the CFD and FEM models (Duthinh et al., 2008). Baum (2011) provides an illustrative example, which is a beam that deflects away from the fire and thus reduces its exposure to the fire. This decrease in temperature will only be considered in a two-way coupled CFD-FEM analysis, with reduced deflection as a result.

Within the European project FIRESTRUC, research has been carried out on several coupled CFD-FEM methods. It was concluded that two-way coupled CFD-FEM analyses are more complex and computationally expensive than one-way coupled analyses (Welch et al., 2008). Nevertheless, a two-way coupled CFD-FEM analysis should be used if changed boundary conditions or a changed geometry of the structure influences the ventilation of the room, and thereby the fire scenario. A clear and comprehensive overview of coupled CFD-FEM methods is given by Tondini et al. (2012).

Feenstra et al. (2018) presented a set of C++ and Python programmes, called FDS-2-Abaqus, which provides two-way coupled CFD-FEM analyses on the overall structural level. A compartment fire was simulated with FDS, and a thermal and structural analysis of a façade was provided by the FEM software Abaqus. The study showed the effects of using a two-way coupled CFD-FEM approach: The failure of a plate led to an opening in the façade, which changed the fire and consequently the façade temperature. As a result, fewer plates failed than for a one-way coupled analysis. However, Feenstra et al. (2018) used an overly simplified model for the façade, only consisting of 12 thin steel plates, which does not provide a reliable view of the structural behaviour of a real façade system. Moreover, no other research can be found in the literature that provides information on the realistic failure modes of complete façade systems for fire resistance. Analyses are often only aimed at the parts of the system, e.g. the thin-walled steel plates, cassettes, purlins, or sandwich panels. Specifically for these last mentioned sandwich panels, research is focused on the thermal response, because a façade system should protect the building occupants against weather conditions and should minimize heat losses through the panel. Nevertheless, an important aspect of a façade system should be the resistance against a fire load (Looyeh et al., 2001), also to avoid further fire spread in the façade.

To contribute to the currently limited knowledge as discussed above, this paper presents a study on the behaviour of a self-supported sandwich panel façade system under fire, based on the model of Feenstra et al. (2018). It should be stressed that the study is aimed at obtaining some new knowledge, rather than geared towards a specific product or its behaviour as interpreted by testing procedures or design codes (Spinardi et al., 2017). First, the new FEM models of a more realistic façade system will be presented, including, among others, purlins, fasteners, the main structure, and material degradation, with the exception of the panel insulation and connections. Namely, for the case study in this article, arbitrarily PIR insulation has been chosen. Although scientific literature provides information on the improvement of some properties of PIR as a function of its chemical composition, e.g. Modesti et al. (2001), Stirna et al. (2011), and Hu et al. (2013), to the best of the authors' knowledge, a systematic description of its thermal and structural properties for the here relevant temperature range is not available. An exception is the work of Wang and Foster (2017), which presents a model for the temperature dependent thermal conductivity of PIR, including some further interesting references. Furthermore, PIR, just like some other insulation materials, will melt at a certain temperature, and can evaporate toxic and explosive gasses. Besides, due to its limited structural properties it may promote delamination of the sandwich skins (e.g. Wang and Foster, 2017) and will have limited strength against e.g. pull-through of the connections. Current knowledge on these issues is very limited. Therefore, in this paper the PIR insulation material is regarded as linear elastic and with constant structural and thermal properties for all temperatures. Also, the focus is put on improving the model of Feenstra et al. by modelling a ventilation- controlled fire and a more detailed model of the façade system with its components and their interaction. As the simulations will show, temperatures are such that melting of the panels will not occur, and failures are due to connection failures caused by constrained thermal expansion of the panels. Finally, experiments have shown that at least for a certain type of façade, at the system level PIR behaves comparably inert and is as safe as stone wool (Guillaume et al., 2018). This together yields the assumptions for the insulation reasonable, but for practical applications, full-scale experiments and detailed panel and insulation tests are definitely needed, and should provide the final answer.

The existing programme FDS-2-Abaqus has been extended with new FEM models and modified coupling programmes, as presented in sections 2 to 4 . In section 5, the actual simulations and parameter studies will be presented, followed by a discussion in section 6 , and conclusions in section 7 . 


\section{Approach}

To achieve the aim of providing a more reliable fire safety analysis for façade systems subjected to fire, several approaches will be compared: A one-way coupled CFD-FEM analysis, a two-way coupled CFD-FEM analysis, and a calculation according to the Eurocode. The programme FDS-2-Abaqus will be used throughout, being a set of C++coded and Python-scripted programmes that perform one-way and two-way coupled CFD-FEM coupling analyses.

In Figure 2, the main procedures of a two-way coupled CFD-FEM simulation are shown, which are: (A1) a fire simulation; (A2) a heat transfer analysis; and (A3) a structural response analysis. These main procedures are coupled by steps (C1) and (C2), and only in the case of a two-way coupled approach, also by (C3). The coupling steps will be described in more detail below.



Figure 2-Main steps of a two-way coupled fire-thermomechanical analysis. C1: Thermal data; C2: Temperatures; C3: Structural changes (two-way coupled only).

\subsection{Coupling of fire simulation to heat transfer analysis (C1)}

For this coupling step, the thermal data from the fire model will be transferred to the heat transfer FEM model using the Adiabatic Surface Temperature (AST) concept presented by Wickström et al. (2007), see also De Boer (2018). Following this concept, the total net heat flux to the surface of the FEM model $q_{\text {tot }}$ in $\left[\mathrm{W} / \mathrm{m}^{2}\right.$ ] equals:

$$
q_{t o t}=\varepsilon \sigma\left(T_{A S T}^{4}-T_{S}^{4}\right)+h_{c v}\left(T_{A S T}-T_{S}\right)
$$

In this equation, $\varepsilon$ equals the emissivity coefficient, $\sigma$ the Stefan-Boltzmann constant $5.6703 \times 10^{-8} \mathrm{~W} /\left(\mathrm{m}^{2} \mathrm{~K}^{4}\right), h_{c v}$ the convective heat transfer coefficient in $\mathrm{W} /\left(\mathrm{m}^{2} \mathrm{~K}\right), T_{S}$ the surface temperature of the FEM model in $\mathrm{K}$, and $T_{A S T}$ the adiabatic surface temperature measured in the fire model, in $\mathrm{K}$. Hence, when the AST is transferred from the fire simulation to the heat transfer analysis, the FEM model can compute the total net heat flux on the façade when the other variables are known. The surface of the façade in the FEM model is divided into partitions, and for each complete partition, the data of a single AST measurement point as defined in the CFD simulation is used, as shown in Figure 3.

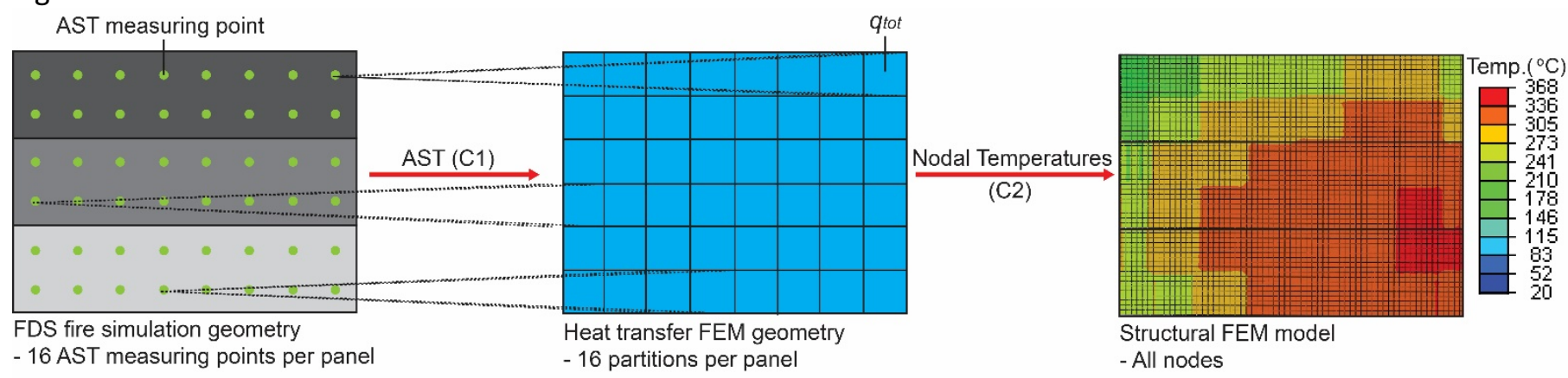

Figure 3 -Data transfer in C1, e.g. for a façade system of three self-supporting sandwich panels, for the structural FEM model temperatures are plotted at time $=30 \mathrm{~s}$ for a typical two-way coupled CFD-FEM analysis. 
Coupling C2 is important as the structural response analysis depends on the temperatures of the structure. Namely, these temperatures will lead to thermal expansion and, if this expansion is restrained or non-linear in any direction, to thermally induced strains and thus stresses. The nodal temperatures from the heat transfer analysis are used as boundary conditions for all nodes in the structural response analysis.

\subsection{Coupling structural analysis to fire simulation (C3)}

Only for a two-way coupled analysis, and after the structural response analysis, failure checks will be carried out to determine whether an opening or other effects in the façade system occur. If positive, this information will be transferred to both the fire and the FEM models, where the failed structural elements are deleted as can be seen in Figure 4.

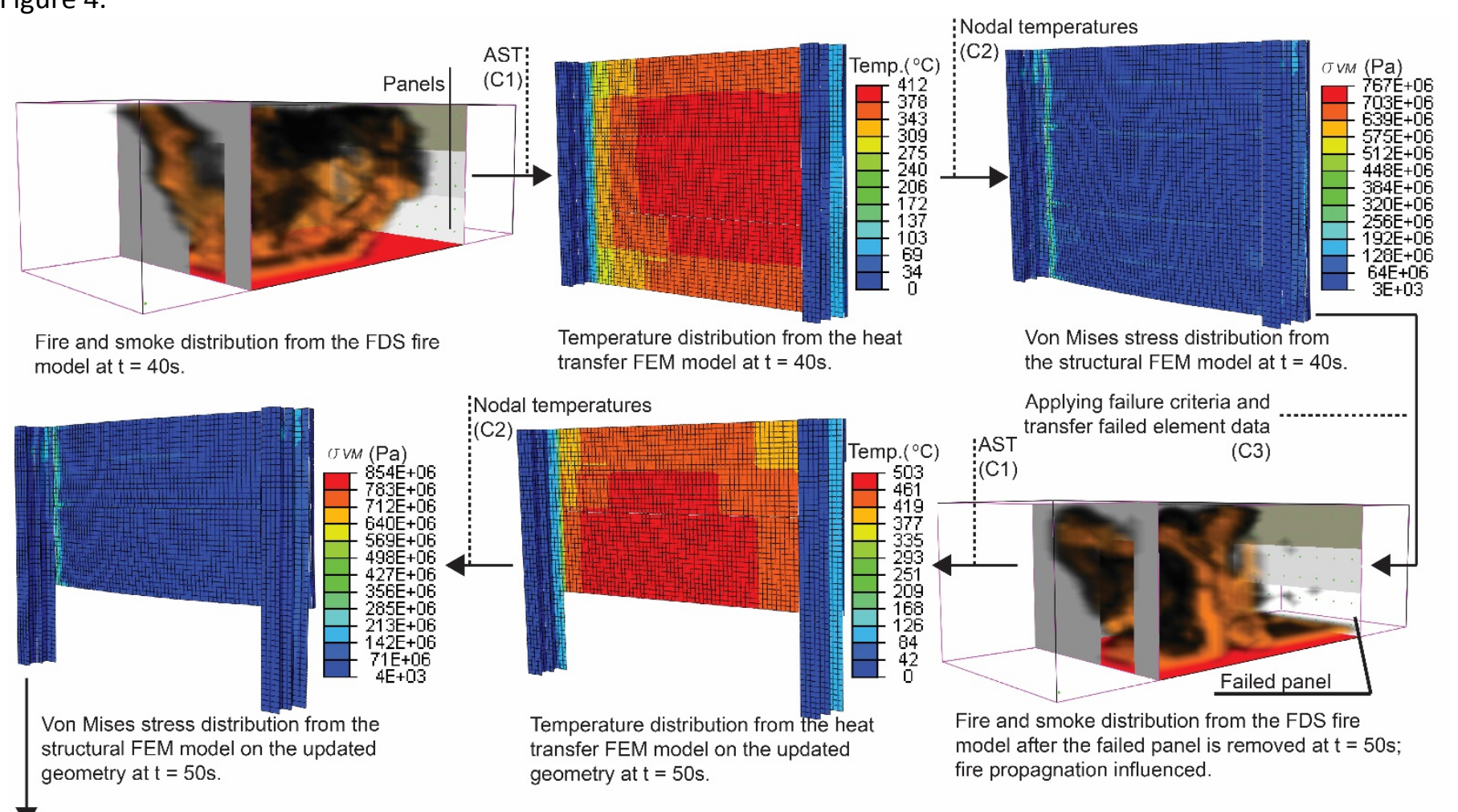

Figure 4-A typical two-way coupled CFD-FEM analysis in which one panel fails (standard analysis, section 5).

\section{Case study}

To investigate the need and effectiveness of a two-way coupled CFD-FEM analysis for façade systems exposed to fire, it is important that a realistic façade system will be modelled. In this section, this façade system and the new required FEM models will be discussed. Although CFD software FDS and FEM software Abaqus were used, a similar approach should be possible with alternative CFD and FEM software programmes.

\subsection{Model room}

Following Feenstra et al. (2018), a standard office is modelled with the following dimensions: $3.6 \mathrm{~m}$ as width, $5.4 \mathrm{~m}$ as length, and $2.7 \mathrm{~m}$ as height. The room has concrete walls and floors. In the wall opposite to the façade, a typical door opening with a width of $0.9 \mathrm{~m}$ and a height of $2.1 \mathrm{~m}$ is modelled.

As shown in Figure 5, the standard façade system consists of three sandwich panels, each $3600 \times 900 \times 80 \mathrm{~mm}$, with an $80 \mathrm{~mm}$ PIR insulation core and outer and inner steel plates, the latter having a thickness of 0.5 and $0.4 \mathrm{~mm}$, respectively. Cold-formed steel angle sections $(150 \times 150 \times 3 \mathrm{~mm})$ connect the panels to the main structure of the HE200A columns. The panels are connected to the angle sections via two screws along the top edge of the panels. Each cold-formed angle section is connected twice with two bolts to a steel lip welded to the main structure columns. 


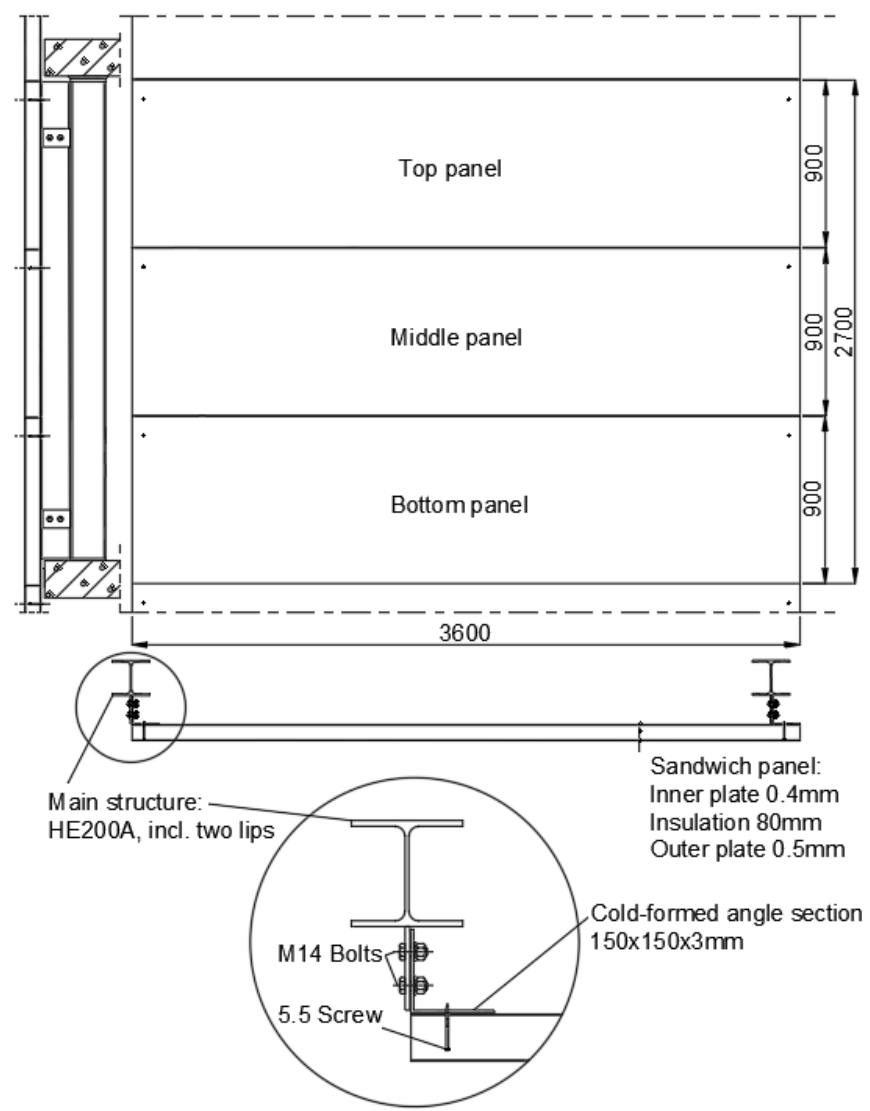

Figure 5-Standard façade system: front view with vertical and horizontal sections, and connection detail.

\subsection{Fire simulation (A1)}

Using Fire Dynamics Simulator (FDS), the office was modelled with a mesh of cuboid cells sized $0.15 \mathrm{~m}$ high, which is for this case a moderate to fine mesh (McGrattan et al., 2013). In the length direction, the computational domain was extended by $1.8 \mathrm{~m}$ on both sides of the room in order to allow air to be drawn into the compartment either through the door or through an opening due to a failed panel. The study of Feenstra et al. (2018) involved a fuelcontrolled fire, which (a) may not be realistic and (b) does not result in a temporarily high heat release rate as a result of a new opening as there is already enough oxygen in the room to combust (Hurley et al., 2016). Therefore, in this study a ventilation-controlled fire was modelled by reducing the door opening width to $0.9 \mathrm{~m}$. Figure 6 plots the Heat Release Rate (HRR) against the time of a resulting FDS fire model. The heat release rate was specified, which means that the fuel flow will be controlled and that the specified heat release rate will be achieved if there is enough oxygen to combust. It can be seen that the model does not reach the specified HRR in the beginning, which shows there is not enough oxygen to combust, and thus the fire simulation is ventilation-controlled. After the failure of the first panel at $t=40 \mathrm{~s}$ a large peak in the heat release rate occurs as the previously unburned fuel will combust in a burst.

Over the complete floor area, a fully developed fire was applied, with its heat release rate for the first 10 seconds linearly increasing to $250 \mathrm{~kW} / \mathrm{m}^{2}$ and hereafter remaining constant. As such, the fire simulation was limited to the flashover and fully developed phase, as prescribed in the Eurocode (EN 1993-1-2, 2005). For the fuel cellulose was selected, with an enthalpy of formation equal to $5.13 \mathrm{~kJ} / \mathrm{mol}$.

In the fire simulation, the façade system consisted of three in FDS so-called obstructions with adiabatic properties. The surface of each panel had sixteen equally spread AST measurement points, which recorded the AST at 5-second intervals. The walls and floors were modelled as obstructions with a thickness of $0.3 \mathrm{~m}$, a density of $1800 \mathrm{~kg} / \mathrm{m}^{3}$, a conductivity of $1.15 \mathrm{~W} /(\mathrm{mK})$, a specific heat of $1.0 \mathrm{~kJ} /(\mathrm{kgK})$, and an emissivity equal to 0.8 . 


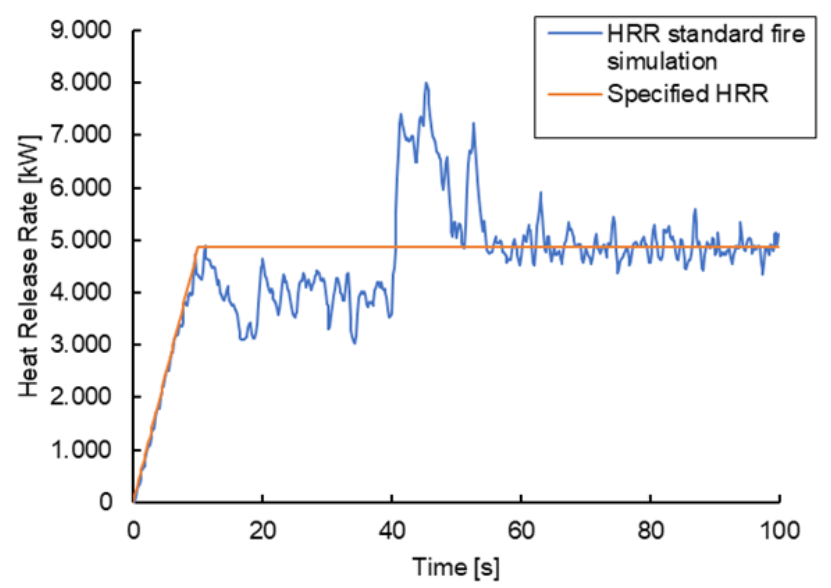

Figure 6-Specified (red) vs. actual (blue) heat release rate for the standard fire simulation as presented in section 5.

\subsection{Heat transfer analysis (A2)}

Figure 7 shows the set-up of the FEM model for the heat transfer analysis. To model the main structure columns, thin-walled angle sections and plates, 8-node heat transfer quadrilateral shells were used (DS8), whereas the PIR core was modelled by 20-node quadratic heat transfer brick elements (DC3D20). Conductivity between the several parts was taken care of by so-called interaction properties, indicated by the bold and red lines in the figure. The outer plates were given a convection coefficient, an ambient temperature, and an emission coefficient as shown in Figure 7 to allow for thermal interaction with the outside air.

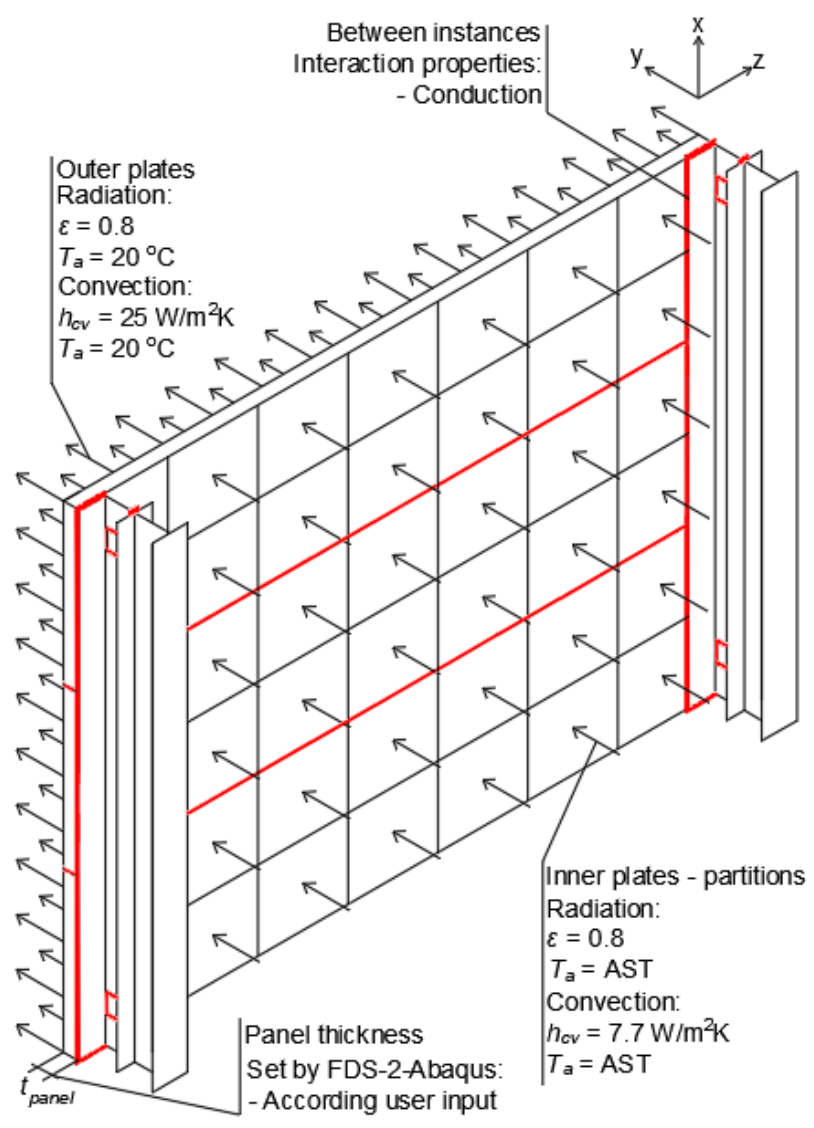

Figure 7 - Set-up of thermal FEM heat transfer analysis model.

The temperature dependent properties of the steel (main structure columns, angle sections, and panel plates) were modelled following the Eurocode (EN 1993-1-2, 2005) as follows. The conductivity is piecewise linear with 53.3 $\mathrm{W} /(\mathrm{mK})$ at $20^{\circ} \mathrm{C}, 27.4 \mathrm{~W} /(\mathrm{mK})$ at $800^{\circ} \mathrm{C}$, and $27.3 \mathrm{~W} /(\mathrm{mK})$ at $1200^{\circ} \mathrm{C}$. Likewise, the specific heat was defined piecewise linear in between the points $440 \mathrm{~J} /(\mathrm{kgK})$ at $20^{\circ} \mathrm{C}, 760$ at 600,5000 at 735 , and $650 \mathrm{~J} /(\mathrm{kgK})$ both at 900 and $1200{ }^{\circ} \mathrm{C}$. The PIR core of the sandwich panels was modelled with ambient properties: a density equal to $45 \mathrm{~kg} / \mathrm{m}^{3}$, a conductivity equal to $0.023 \mathrm{~W} /(\mathrm{mK})$, and a specific heat of $1400 \mathrm{~J} /(\mathrm{kgK})$. 
For the first study, the ISO-834 fire curve was used to apply the temperature $T$ in ${ }^{\circ} \mathrm{C}$ below as a boundary condition on the inner plates of the façade system, with the time $t$ here in min.

$$
T=20+345 \cdot \log (8 t+1)
$$

For the other studies, heat flux $q_{\text {tot }}$ was applied to the inner plates of the façade panels, following the procedure as shown in Figure 3. For this, equation (1) was used with the emissivity $\varepsilon$ equal to 0.8 and a convective heat transfer coefficient equal to $h_{c v}=7.5 \mathrm{~W} /\left(\mathrm{m}^{2} \mathrm{~K}\right)$. In all cases, the heat transfer analysis was transient, to take into account the heat capacity of the structure.

The heat transfer FEM model was first verified by a steady-state simulation in which one side of the panels was given an increased temperature and the resulting temperature distribution and fluxes over the cross-section were compared with theory. Secondly, by increasing the temperature of a single panel, again steady-state, the interaction properties between the panels, and radiation and convection behaviour to the outside were verified. More details can be found in De Boer (2018).

\subsection{Structural response analysis (A3)}

In the model for the structural response analysis, see Figure 8 , the columns, angle sections, and the plates of the sandwich panels were modelled with eight-node quadratic shell elements (Abaqus: S8R), and the PIR core with 20node quadratic brick elements (C3D20). The mesh size was $100 \times 100 \mathrm{~mm}$ for the outer plates and $50 \times 50 \mathrm{~mm}$ for the inner plates, the angle sections, and the main structure columns, including the lips. The $80 \mathrm{~mm}$ thick core was meshed with $100 \times 100 \times 40 \mathrm{~mm}$ sized elements.

The actual sandwich panels use a tongue and groove connection along the longitudinal edges. In the FEM model this was modelled by spring elements, each connected to a node at the bottom of an outer plate and to a node at the top of an inner plate, see Figure 9, which provided out-of-plane stiffness. The connections between the panels and the angle sections were modelled with Abaqus specific "wire sets" and between the angle sections and main columns by Abaqus specific "fastener constraints", all with a "connector" used for their "section". Practically, this allowed for modelling a stiffness for each connection in the $x, y$, and $z$-directions, the values determined by the Eurocode "component method" (EN 1993-1-8, 2005), details of which will be provided in the next sections. To fix the complete model in space, all nodes on the lines at the bottom of the main structure columns were restrained in $x, y$, and $z$-directions, whereas the nodes on the lines at the top were restrained in $y$ and $z$-directions only, to allow for expansion in the length direction. Finally, contact between the various parts was modelled by Abaqus specific "hard contact interaction properties" between surfaces. The surfaces are shown in Figure 8 by bold and blue lines.

For the steel of the panel plates, angle sections, and main structure columns, temperature dependent properties were taken into account (EN 1993-1-2, 2005): With a constant Poisson ratio of 0.3 and density of $7850 \mathrm{~kg} / \mathrm{m}^{3}$, Young's modulus was a constant $210000 \mathrm{~N} / \mathrm{mm}^{2}$ up to $100{ }^{\circ} \mathrm{C}$ and hereafter piecewise linear between the points $\left(500{ }^{\circ} \mathrm{C}, 126000 \mathrm{~N} / \mathrm{mm}^{2}\right),(600,63000),(700,32000)$, and $(1000,10000)$. Similarly for the yield strength, this was 355 $\mathrm{N} / \mathrm{mm}^{2}$ constant up to $400{ }^{\circ} \mathrm{C}$ and hereafter piecewise linear in between $\left(600{ }^{\circ} \mathrm{C}, 177 \mathrm{~N} / \mathrm{mm}^{2}\right),(700,88.8),(800$, $35.5)$, and $(1000,17.8)$. The thermal expansion coefficient was $1.5 \times 10^{-5} 1 / \mathrm{K}$ between 20 and $750{ }^{\circ} \mathrm{C}, 1.3 \times 10^{-5} 1 / \mathrm{K}$ for $750-860{ }^{\circ} \mathrm{C}$, and again $1.5 \times 10^{-5} 1 / \mathrm{K}$ for $860-1200{ }^{\circ} \mathrm{C}$. The PIR core was modelled with a Young's modulus equal to $20000 \mathrm{~N} / \mathrm{mm}^{2}$, a Poisson ratio of 0.2 , a density equal to $45 \mathrm{~kg} / \mathrm{m}^{3}$, and a thermal expansion coefficient equal to $5.0 \times 10^{-5} 1 / \mathrm{K}$, which were all ambient properties.

To ensure convergence and to make the model more realistic, an initial imperfection was applied by using the first Eigenmode of the whole structure, found by the subspace method, with its maximum displacement equal to $3 \mathrm{~mm}$. The FEM model was loaded by using the results of the heat transfer analysis, the nodal temperatures, as an Abaqus predefined field.

If structural elements fail in the two-way coupled CFD-FEM analysis, they should be deleted in the FEM model. To accommodate this process, the inner and outer plates and the core of a single panel were grouped into a single "set". Furthermore, for the connections (e.g. between a panel and an angle section), Abaqus specific "wire sets" are chosen, which can be deactivated in the FEM model. 
The solution was found by a general static approach using the Newton-Raphson method and taking into account material and geometrical non-linearity. Details of a validation of the model, comparing the theoretical deflection due to a wind load with the numerical results, can be found in De Boer (2018).

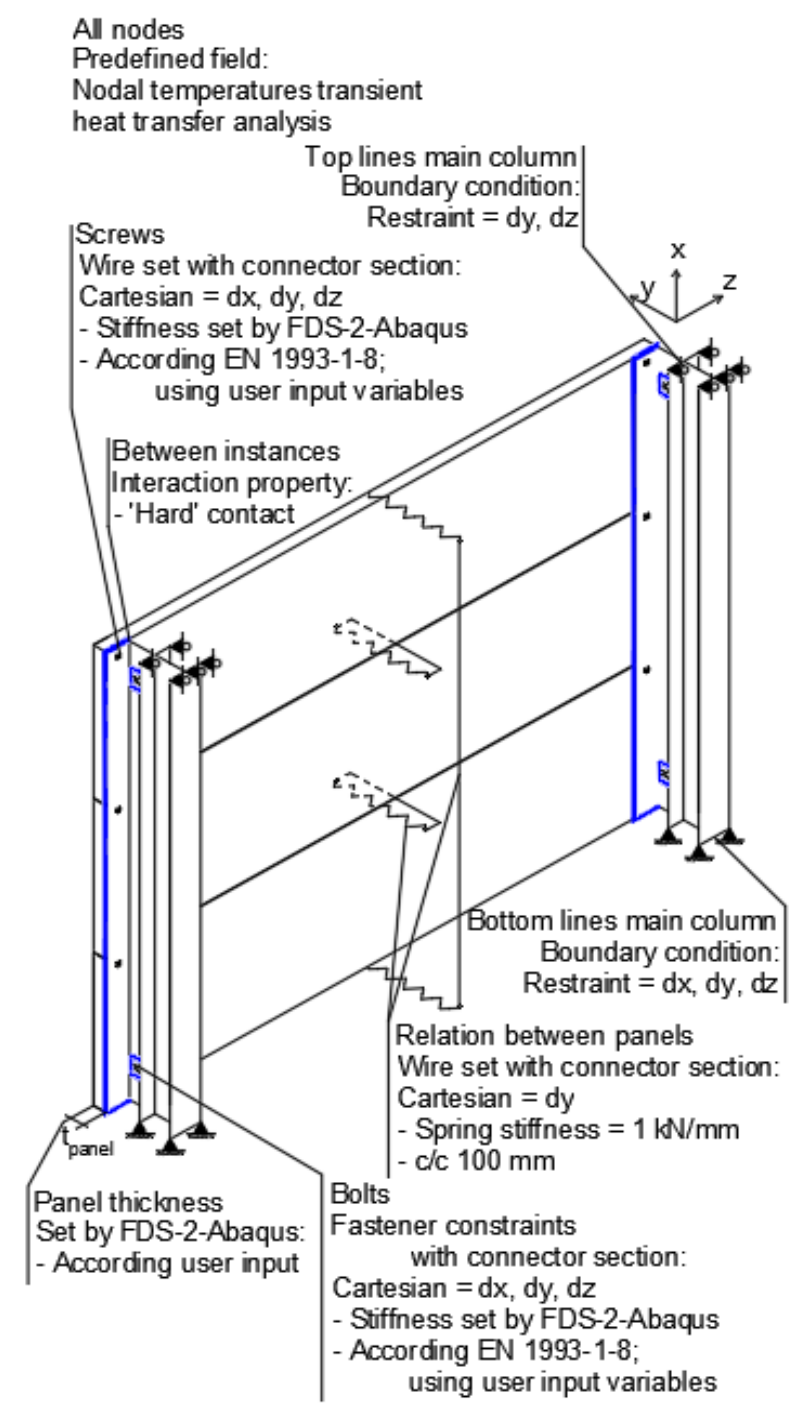

Figure 8-Set-up of structural FEM model.

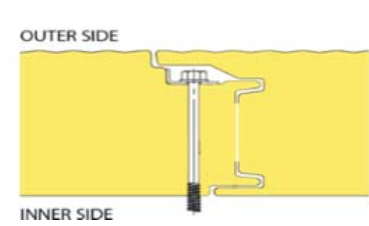

a.

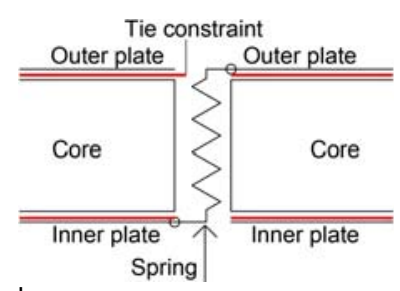

b.

Figure 9-Tongue and groove connection between sandwich panels on the left, right: its FEM model using springs.

\subsection{Failure modes}

Four categories of failure modes exist for a façade system resisting fire. In the following subsections, each category will be presented, and its equations will be evaluated for the standard façade system.

\subsubsection{Panel failure}

If the inner plate of a panel has a higher temperature than the outer plate, the panel will bend, with related strains and possible rupture as a result (Usmani et al., 2001). Failure due to rupture can be checked by a maximal panel 
deflection as shown in Table 1 and equation (3), (EN 14509:2013). Note that in the simulations, the steel plates have thermal and mechanical non-linear properties, e.g. the steel plates may yield and their yield stress depends on their temperature.

Table 1-Panel failure (EN 14509:2013).

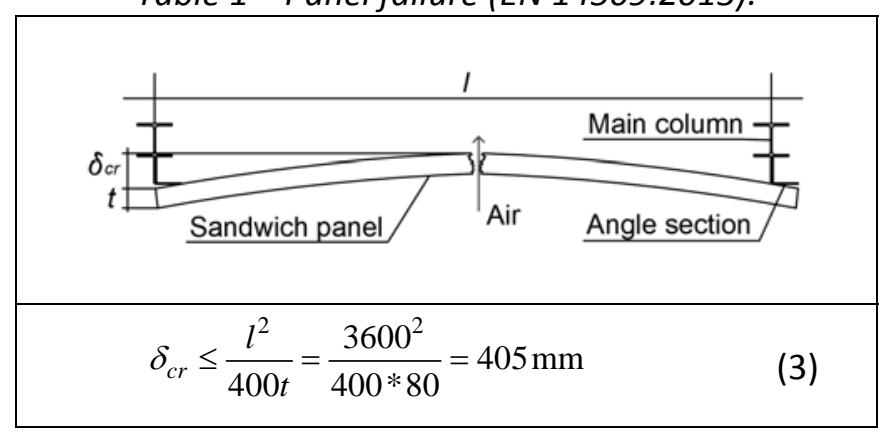

\subsubsection{Façade openings}

Because of the deformations of the structure and panel bending in both directions, a gap or opening between the panels may occur, which in turn will affect the fire behaviour. Given the height of the specific tongue and groove connection ( $46 \mathrm{~mm}$ ), no opening occurs if the difference between node 1 and 2 (see Table 2) displacements is smaller than the tongue height, as shown in Table 2 and equation (4).

Table 2 -Opening between two panels and the maximum relative displacement before an opening will occur.

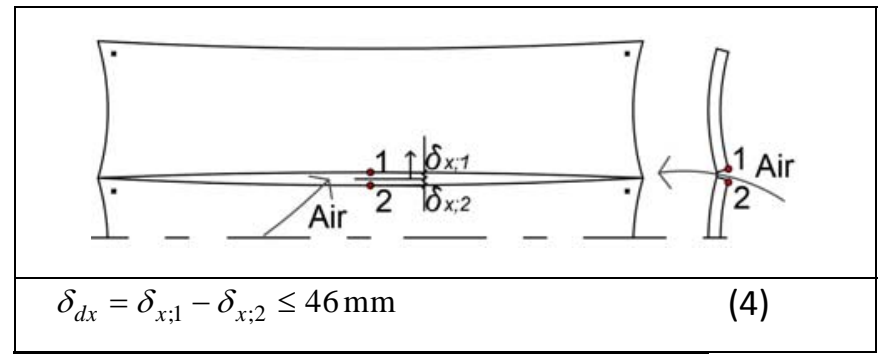

\subsubsection{Panel - Angle section screw failure}

During construction, a panel is positioned with its bottom on top of another panel below, using the tongue and groove connection, and subsequently the panel is fixed along the top by two screws, one for each angle section, see Figures 8 and 9. Table 3 shows the possible failure modes and accompanying loads for this screw connection. For the equations, not the Eurocode for steel cold-formed members and sheeting has been used (EN 1993-1-3, 2006), as that code requires tests for screw tension and shear resistance. Instead, the Eurocode for aluminium structures is applied (EN 1994-1-4, 2007), as it does not require tests for tension and shear resistance, and covers all other failure modes of EN 1993-1-3, with explicit allowance for the use of supporting members of steel, thus providing a single consistent set of formulae. Bearing is checked for the angle section and is assumed to be safe for the sandwich panel. Therefore, in equation (7), for the thickness the angle section thickness is used. For the pull-out strength of the thin-walled angle section, the screw diameter $t$ of $5.5 \mathrm{~mm}$ is not completely within the allowed range (6.25-6.5 $\mathrm{mm}$ ), but the equations are still used for the lack of more appropriate rules. In Table $3, F_{v ; E d}[\mathrm{~N}]$ is the shear force and $F_{t ; E d}[\mathrm{~N}]$ is the tension force in the screw, $F_{v ; R d}[\mathrm{~N}]$ is the shear resistance and $F_{t ; R d}[\mathrm{~N}]$ is the tension resistance, predicted in the second and fourth rows of the table. The cross-sectional area of the screw is given by $A_{s}\left[\mathrm{~mm}^{2}\right]$ and $\gamma_{m 3}$ is the partial safety factor for screws, equal to 1.25. For the calculation of the bearing resistance $F_{b ; R d}[\mathrm{~N}]$ and the pull-out resistance $F_{p ; R d}[\mathrm{~N}]$, the following additional variables are used: $f_{u}\left[\mathrm{~N} / \mathrm{mm}^{2}\right]$, which is the ultimate strength of the screw; $f_{u \text {; sup }}\left[\mathrm{N} / \mathrm{mm}^{2}\right]$, which is the ultimate strength of the support structure material; $d$, the screw diameter $[\mathrm{mm}]$; and $t_{\text {sup }}[\mathrm{mm}]$, the plate thickness of the supporting structure. Temperature dependency for the variables in Table 3 has not been taken into account because (a) the connections are modelled in Abaqus with so-called "wire sets" and "fastener constraints", which do not have a temperature (distribution), and (b) similar to the PIR-panels, temperature dependent bearing, pull-through, etc. is largely an unknown territory, and so it is impossible to provide sensible input for these phenomena, except for the currently accepted design codes. This also applies to the bolt connections. 
Table 3 - Panel - Angle section screw failure modes (EN 1999-1-4, 2007).

\begin{tabular}{|l|l|}
\hline & $\frac{F_{v ; E d}}{F_{v ; R d}}+\frac{F_{t ; E d}}{1.4 F_{t ; R d}} \leq 1.0$ \\
\hline
\end{tabular}

\subsubsection{Main structure column - Angle section bolt failure}

The angle sections, made from cold-formed steel, are fixed to the main structure columns using M14 8.8-steel bolts. Table 4 presents the bolt failure modes according to Eurocode (EN 1993-1-8, 2005). Newly introduced variables are the ultimate tensile strength of the bolt $f_{u b}\left[\mathrm{~N} / \mathrm{mm}^{2}\right] ; \alpha_{v}$ is a material factor according to the steel quality class; $k_{2}$ is a reduction factor according to the bolt geometry; and $\gamma_{m 2}$ is the partial safety factor for screws, equal to 1.25 . For bearing failure, $\alpha_{b}$ takes into account the materials of the bolt and angle section, and the edge distance of the bolt in the load direction, whereas $k_{1}$ is related to the edge distance in the perpendicular direction. Finally, for the calculation of the pull-through resistance, $d_{m}$ is the thickness of the washer. 
Table 4 - Main structure column - Angle section failure modes (EN 1993-1-8, 2005).

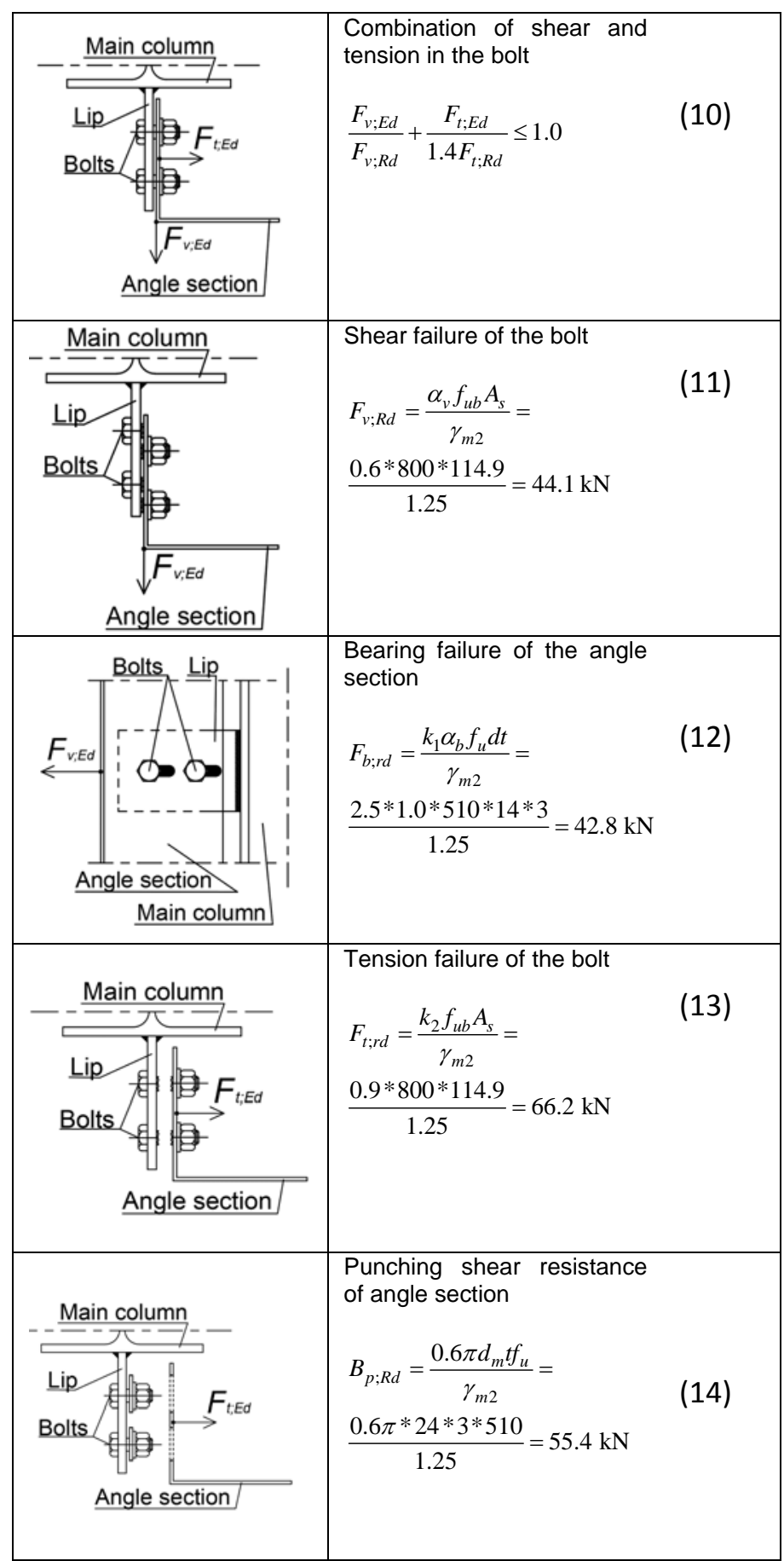

\subsubsection{Consequences of failure checks}

Based on all the above failure checks:

(a) A panel will be removed if the maximal panel deflection is exceeded as given by equation 3. It is realised that removing a complete panel just because a maximal deflection is exceeded is far from realistic. Namely, even though the steel plates are modelled with temperature dependent thermal and mechanical properties, a sandwich panel may show additional complex behaviour due to insulation material non-linearities and pyrolysis, and (local) delamination. However, as mentioned earlier, this paper presents research on the improvement of a two-way coupled CFD-FEM simulation approach, with a focus on the introduction of failure checks for each of the components as part of the façade system. Due to its very complex behaviour, the sandwich panel component has so far been implemented with a single and simple failure criterion. However, the modelled behaviour, possibly leading to this criterion, is based on thermal and mechanical nonlinear material properties, with the exception of the insulation. 
(b) An opening will be created if the distance between the panels is larger than that given by equation 4 . This equation has been implemented and is checked during simulations. However, because in the cases studies the distance between the panels was never larger than the critical value, the actual creation of openings was not implemented. The discussion in Chapter 6 presents a preliminary study on the effects of an opening.

(c) A panel is removed if both screws of a panel fail as checked in Table 3. It should be realised that even if both screws fail, a panel may still be kept in position thanks to the adjacent panels and the tongue and groove connections.

(d) Most realistically, compared to the above actions (a) to (c), all panels and columns are removed if all bolts fail as checked in Table 4.

\subsubsection{Load and displacement-based failure checks}

Tables 3 and 4 present formulae that are expressed in terms of force. Therefore, in the simulations the forces in the (linearly and elastically modelled) screws and bolts are checked against the allowable forces given by the formulae. Additionally, a displacement-based strategy has been implemented. For that strategy, screw and bolt behaviour are modelled as elasto-rigid plastic, as shown in Figure 10. The axial and transverse stiffness $\left(S_{t}\right.$ and $\left.S_{v}\right)$ are equal to the standard strategy; the rigid plastic level is based on the formulae in Tables 3 and 4; and the allowable axial strain of screws and bolts $\varepsilon_{c r}$ is set to 0.12 , and the allowable failure strain $\gamma_{c r}$ equals 0.24 , according to ISO 898-1 (2013). Consequently, in the simulations the deformations of the screws and bolts are monitored, translated into strains, and these strains are checked with the allowable strains. Note that the allowable strain for the interaction of axial and transverse strains is based on equations (5) and (10), with forces substituted by strains.

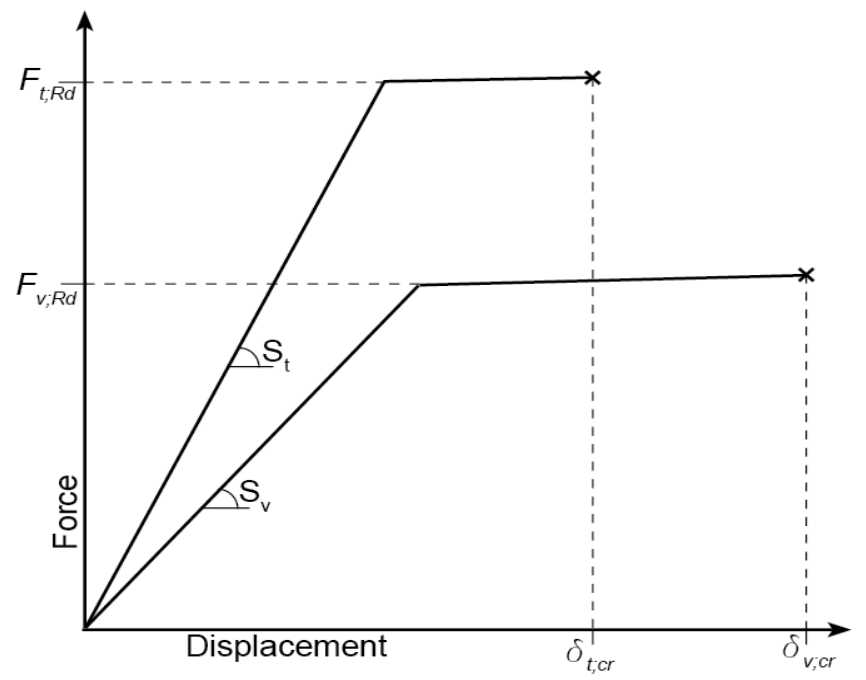

Figure 10 - Force-displacement behaviour for connections under tension ( $t$ ) or shear $(v)$.

\section{Programmes and scripts}

The CFD-FEM analyses presented in this paper were carried out with FDS, Abaqus, and FDS-2-Abaqus (Feenstra et al., 2018), the latter being a set of C++ and Python coded scripts, see Figure 11. FDS-2-Abaqus was initially developed to show the importance of two-way coupling on the overall structural level. As such, it was only capable of showing this for an academic modelled façade system with a single failure criterion. For a more realistic sandwich panel façade as used in this paper, specific scripts needed further development, as presented in this section. Further details can be found in Feenstra et al. (2018) and De Boer et al. (2018).

\section{1 upGeomFDS}

Managed by FDS-2-Abaqus as shown in Figure 11, upGeomFDS creates an input file for an FDS simulation. The same basic file is used for each iteration, which contains the geometry, discretization, fire definition, and so-called AST output devices. For a specific iteration, the file is then modified to take into account the removal of the sandwich 
panels, by appending the code to deactivate the failed panel. While the fire simulation and the geometry in this paper are different from Feenstra et al. (2018), the upGeomFDS scripts are very similar.

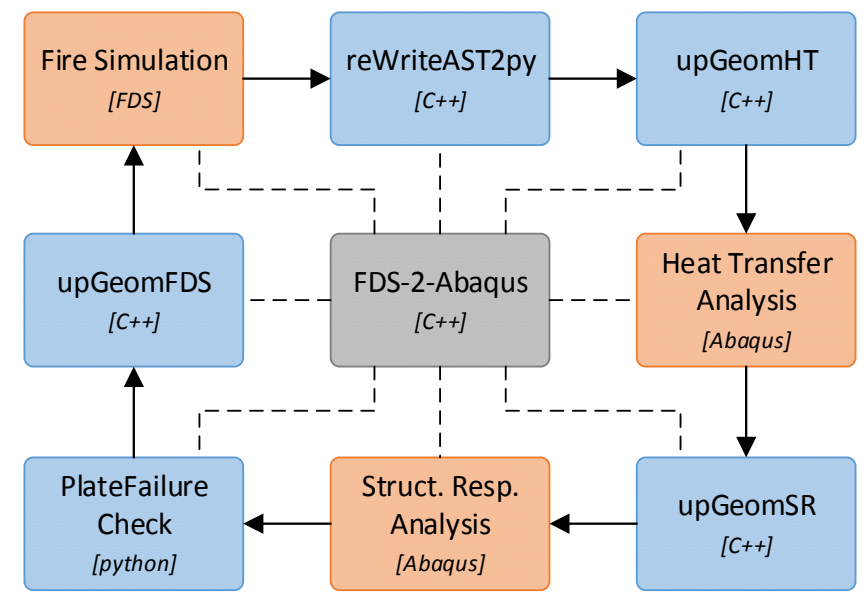

Figure 11 - Overview of FDS-2-Abaqus, analysis programmes (orange) and coupling programmes (blue), Feenstra et al. (2018).

\section{2 reWriteAST2py}

The FDS output file contains AST data as comma separate values (csv-file), which will be translated into a Python script that can be read by Abaqus. Again, the reWriteAST2py script is very similar to the one used in Feenstra et al. (2018).

\section{3 upGeomHT}

The programme upGeomHT creates the Python input script for the FEM heat transfer model. Similar to upGeomFDS, a basic Python script is used, which contains the geometry; the subdivision of the inner plates each into sixteen partitions as shown in Figure 3; section properties; material characteristics; and the mesh size. Then this basic script is amended with the so-called interaction properties, which define for each time step the radiation and convection properties of the outer plates and the conductance between the parts. Furthermore, the programme appends data to set the radiation and convection heat fluxes, as interaction properties to the inner plates, and modifies the model for a user given panel thickness. Finally, if a failure mode occurs that leads to the removal of a sandwich panel, the sandwich panel will be deleted from the heat transfer analysis as well. For this purpose, in the basic script a set is defined that contains all the parts that belong to a single panel. This set can be deactivated by a so-called Abaqus "model change interaction". To avoid convergence problems, the interaction properties related to these parts should also be inactivated. The implementation of the AST temperature data follows the same concept as Feenstra et al. (2018). However, the addition and/or deactivation of several interaction properties is new and necessary (a) to build the FEM model of a more realistic façade system and (b) to delete the façade panels after failure. A flowchart of upGeomHT, its C++ code, and basic and appended output scripts can be found in De Boer (2018).

\section{4 upGeomSR}

This programme copies a basic script and modifies it to restart the structural response analysis for each iteration. The basic script contains the geometry of the FEM model; section properties; material characteristics; and the mesh size, however, without the partitioning of the inner plates. Furthermore, the boundary conditions, initial imperfections, panel sets, and wire sets with a connector property (for the connections) are already defined. This basic script will then be modified for each step by (a) the introduction of contact properties between the parts; (b) the deletion of the initial imperfections after the first iteration; and likewise Feenstra et al. (2018): (c) the update of nodal temperatures from the heat transfer analysis. Different from Feenstra et al. (2018), the programme now handles parametric screw and bolt diameters, and a parametric panel thickness. For the former, the non-linear behaviour is determined, according to EN 1999-1-4 (2007) (Table 3), EN-1993-1-8 (2005) (Table 4), and Figure 10. If a sandwich panel falls off, this programme will deactivate the "set" of this panel. Similar to the heat transfer analysis, then also the "wire sets", which are used to model the screws and tongue and groove connections, and the "hard 
contact" interaction properties (the surfaces shown in Figure 8 by bold blue lines) are deactivated. A flowchart of the upGeomSR programme, its C++ code, and the basic and appended scripts can be found in De Boer (2018).

\section{5 plateFailureCheck.py}

Compared to Feenstra et al. (2018), the Python programme plateFailureCheck.py is completely different. It uses the results of the FEM structural model to perform the Eurocode checks presented in section 3.5. The Python script will extract all nodal displacements per panel and will store these in data containers. The same applies to the relative displacements between the screw and bolt nodes. For each panel, and for each screw and bolt, the formulae as presented in section 3.5 will be solved by using the corresponding data container in order to determine whether one of the failure models will occur. A failure will be recorded with its mode, time, panel id, and screw or bolt id. This information is further used and recorded by the main programme FDS-2-Abaqus. Consequently, the failed panel is removed from further iterations. A flowchart of plateFailureCheck.py and the main programme can be found in De Boer (2018).

\section{Simulations}

The approach presented in section 2 was used for several parameter studies for the case study given in section 3 , with the programmes and scripts as explained in section 4. If not indicated otherwise, for the variables, standard values were used as listed in section 3, e.g. M14 bolts, 5.5 screws, and a panel thickness of $80 \mathrm{~mm}$. For the standard approach, which is also the default setting of FDS-2-Abaqus, a two-way CFD-FEM coupling analysis was performed, using a ventilation-controlled fire simulation, and displacement-controlled screw and bolt failure checks. Each analysis was carried out only once, however, it should be noted that the outcomes of several runs of exactly the same fire simulation yield slightly different outcomes due to random effects in the CFD-simulations (Feenstra et al., 2018).

\subsection{Analysis approach}

To study the thermal and structural behaviour of the façade system under fire, three different analysis approaches have been studied: (I) A one-way coupled analysis for which the CFD fire simulation was replaced by the ISO-834 fire curve (eq. (2)) uniformly applied to the façade inner side; (II) a one-way coupled analysis; and (III) a two-way coupled analysis, the last two as presented in this paper and including CFD fire analyses. Plate failures for the different approaches are shown in Figure 12, and typical temperature contours are visualised in Figure 13. Note that the failure times are very short compared to tests on individual components. For example, some sandwich panels may achieve 120 minutes integrity (E) and 15 minutes insulation (I), as mounted and fixed normally for a fire test. Besides the fact that the CFD fire starts at flashover, and the ISO curve is applied directly to the structure, which is unrealistic, the short failure times can be explained further: Heating leads quickly to strong expansion of the sandwich panels, which imposes very high levels of stress on the two little screws.

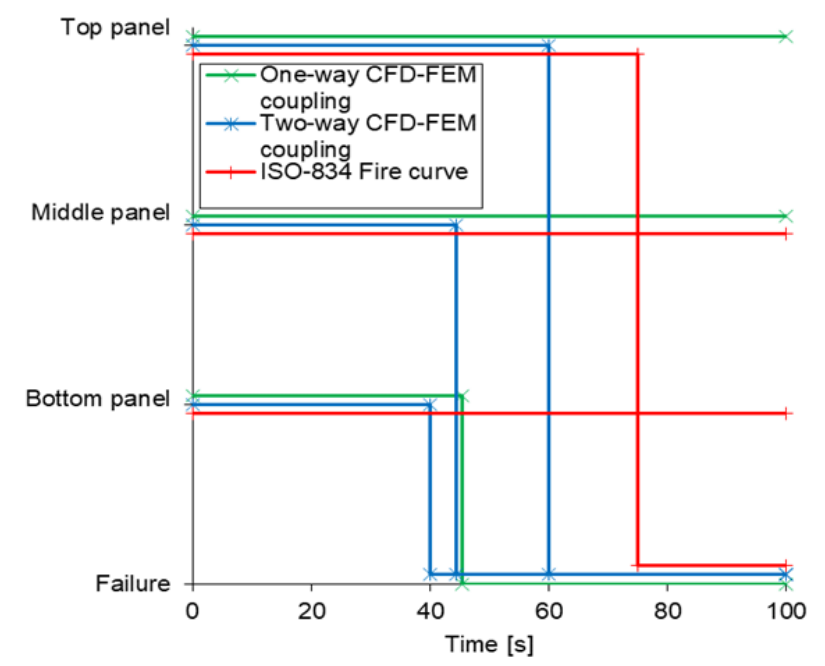

Figure 12 - Panel failure for the three different simulation approaches. 


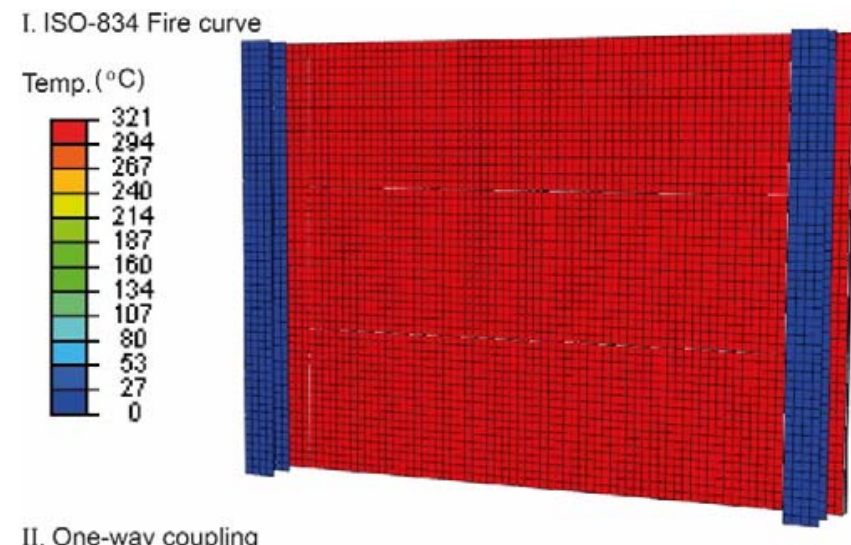

II. One-way coupling


Figure 13 - Temperature distribution at $t=45 \mathrm{~s}$.

All failure events, for all three approaches, related to both screws of a panel failing due to large transverse strains, caused by the thermal expansion of the façade panels. For approach (I), in this way only the top panel failed, somewhat surprisingly because the temperature distribution was equal for all of the panels. However, the panels are connected to the thin-walled angle sections. The top panel is fixed close to where these angle sections themselves are fixed to the main structure columns. This means thermal expansion of the top façade panels can only be handled by the screw itself, and not additionally by some bending flexibility of the angle section, as is the case for the middle and bottom panels. Compared to (I), approach (II) inevitably showed a non-uniform temperature distribution over the façade parts, and consequently the bottom panel failed. Differently for the two-way coupled analysis (III), the removal of the bottom panel after the failure of its two screws led to a higher heat release rate close to the façade, due to the extra oxygen that flowed in from the opening. It can be seen in Figure 13 that after the bottom panel was removed the temperature distribution of the middle panel changed, and that the maximal temperature was higher (471 vs. $439{ }^{\circ} \mathrm{C}$ ) compared to the middle panel in the one-way coupled analysis. Meanwhile in the structural simulation, the middle panel lost its structural restraint from the bottom panel, and was thus able to straighten. Together with the increasing temperature this led to the failure of the screws of the middle panel first, followed by failure of the top panel last.

\subsection{Screw diameter}

Making use of the parametric model in FDS-2-Abaqus, two-way coupled CFD-FEM analyses were carried out for three different screw diameters, as shown in Figures 14 and 15. The structural response using 4.8 screws was similar 
to the standard simulation using 5.5 screws, only the failure started earlier for each panel. The simulation with 6.3 screws did not show failures at all. The relative traverse displacement between the start and end nodes of the connector modelling the screw, at the bottom panel, can be seen in Figure 15.

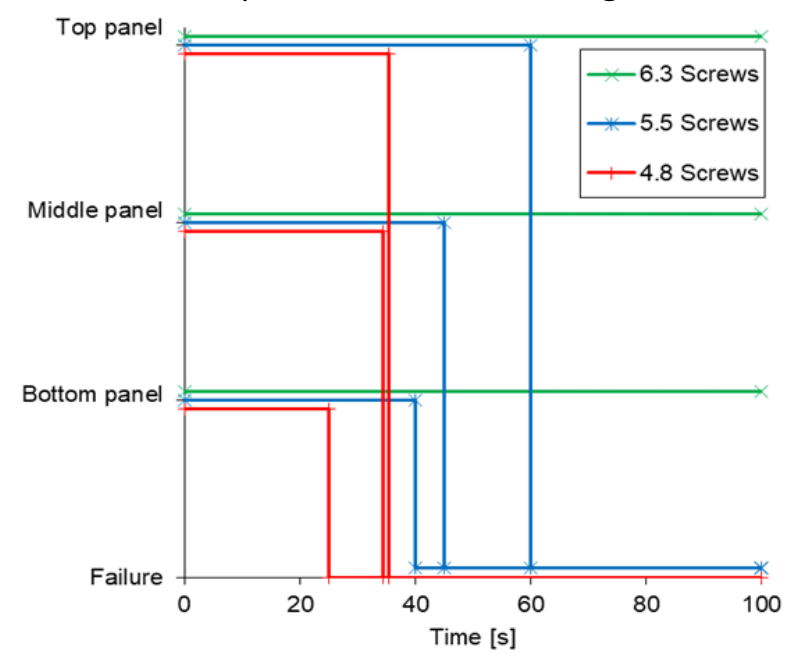

Figure 14 - Panel failure for different screw diameters.

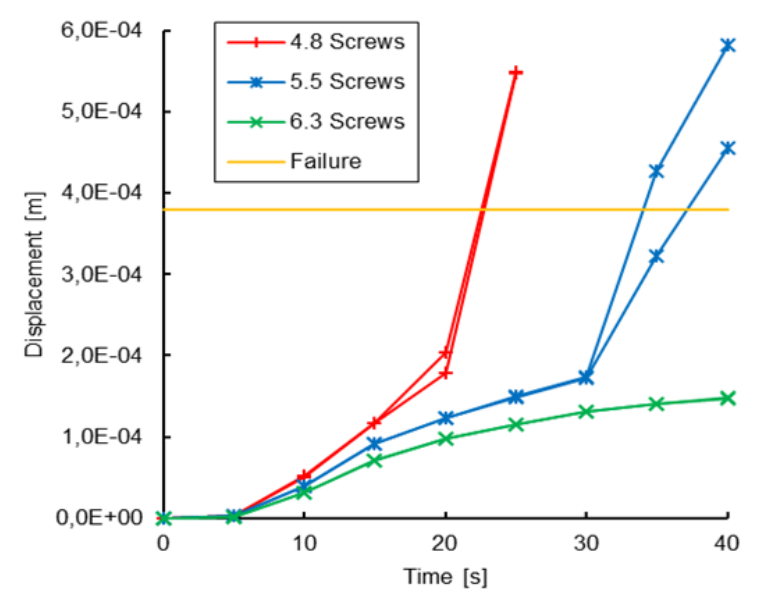

Figure 15 - Relative displacement of the screw nodes of the bottom panel using different screw diameters.

\subsection{Force instead of displacement-based failure checks}

According to the Eurocode, the screw and bolt failure checks are load-based, as shown in Tables 3 and 4. However, the modelled behaviour as given in Figure 10 shows that after the predicted failure load, ductility allows for further displacements. To investigate whether this influences panel behaviour, the standard simulation, using displacement based checks as default, was also carried out using force-based failure checks as explained in section 3.5.6, see Figure 16. The panel failure sequence is the same for both simulation types; however, the more realistic displacement-based criteria resulted in slightly delayed failure.

\subsection{Fuel- vs. ventilation-controlled fire}

Feenstra et al. (2018) used a fuel-controlled fire simulation, whereas this study uses a more realistic ventilationcontrolled fire simulation, which was discussed in section 3.2. A review of the differences in fire behaviour can be found in De Boer (2018), while in this section the structural behaviour for the different fire scenarios will be discussed. Before panel failure, the fuel-controlled fire is situated close to the façade because of the airflow into the room through the large door that provides a large amount of oxygen as can be seen in Figure 17a. This leads to high temperatures at the façade and thus fast failure initiation. While in the ventilation-controlled fire, the fire is located in the centre of the room and burns across the door in search of oxygen. At the same time, air flows into the room via the bottom of the door opening, as shown in Figure 17c. After the failure of the first panel, the fuel-controlled fire will be present only in the middle of the room (Figure 17b), while for the ventilation-controlled fire this will happen only after the failure of 2 panels, because only then is there enough oxygen to combust and the fire will also be fuel-controlled. Furthermore, for ventilation control there will be a high heat release rate (Figure 6) after the 
removal of the first panel, which results in the relative fast failure of the other two panels. This can be seen clearly in Figure 18.

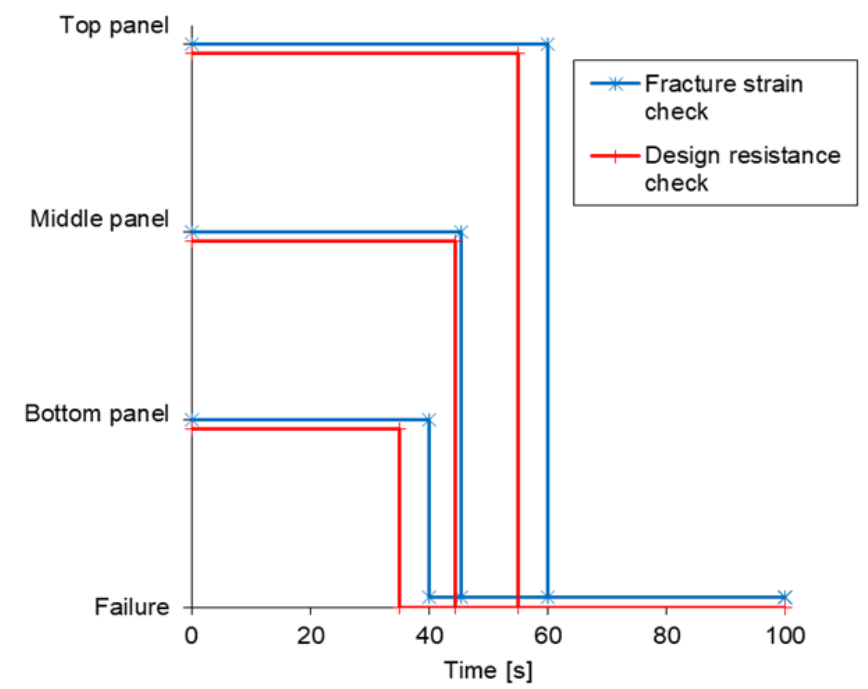

Figure 16 - Panel failure for load (resistance) based checks and displacement (strain) based checks.

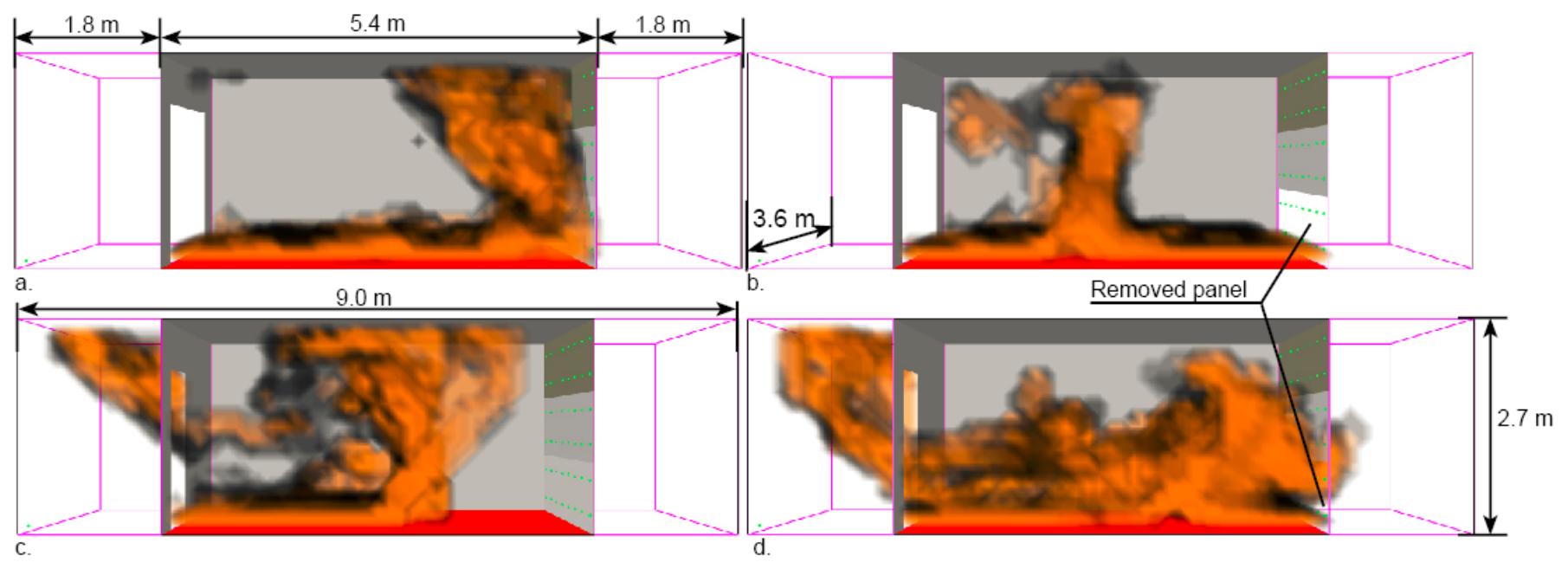

Figure 17-Fuel-controlled fire at (a) $t=29 \mathrm{~s}$ and (b) $t=33$, ventilation-controlled (c) $t=29$ and (d) $t=43 \mathrm{~s}$.

\subsection{Panel thickness}

Three different panel thicknesses have been studied for their influence on the structural response. Plate failure sequences are shown in Figure 19. The façade panels with a thickness of $100 \mathrm{~mm}$ show the same failure progression as the standard $80 \mathrm{~mm}$ thick panels, however, failure occurs earlier. Interestingly, the thin panels, with a thickness of $60 \mathrm{~mm}$, do not show any failure. To understand this, panel out-of-plane deflections are plotted in Figure 20. It can be seen that thicker panels deflect less, due to their higher stiffness. However, deflection of the panels is actually favourable for the screws, as seen in Usmani et al. (2001) and Figure 21. In these cases the displacement due to the thermal expansion $\left(\delta_{T E}\right)$ at the connection (roller support) is compensated more by the displacement in the opposite direction due to the thermal bowing $\left(\delta_{T B}\right)$. Hence, if thermal bowing is larger, which is the case for thinner panels with a lower bending stiffness, the screw is loaded less in shear. 


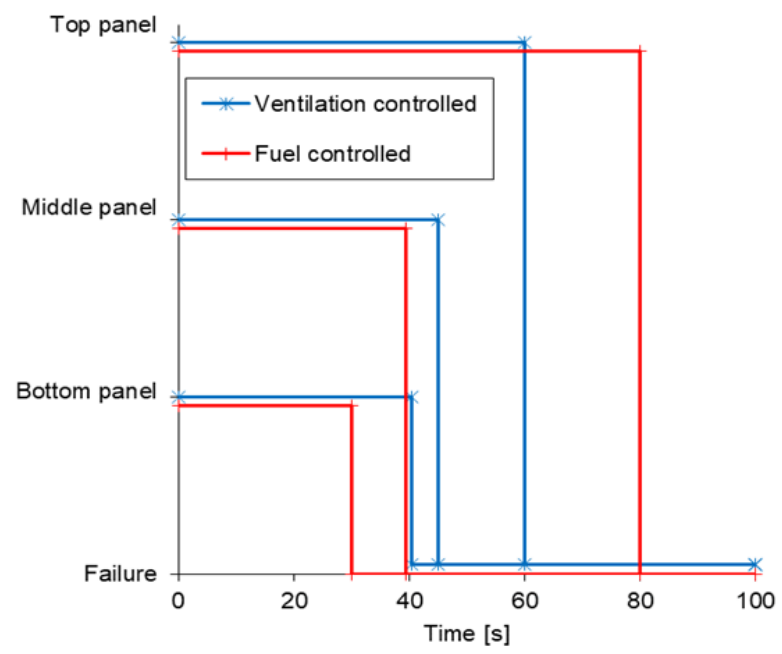

Figure 18 - Panel failure for fuel- and ventilation-controlled fires.

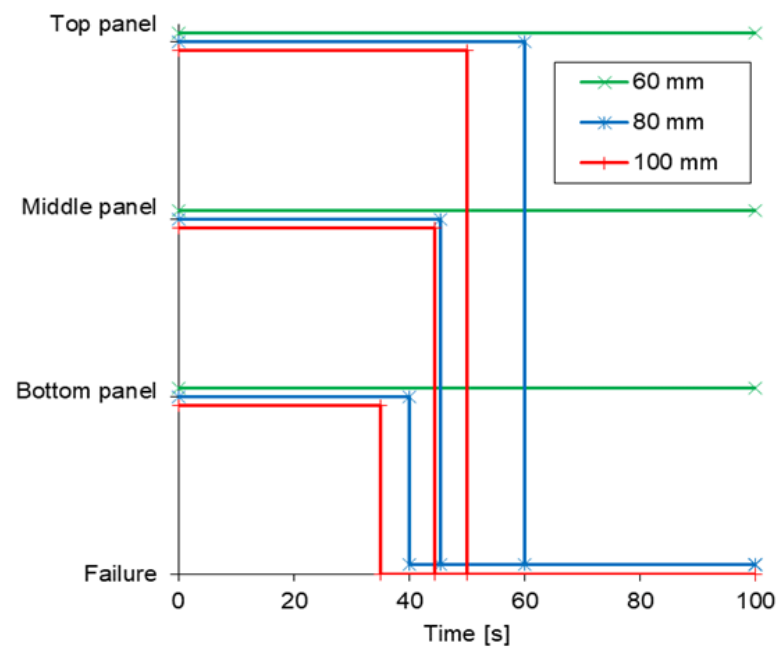

Figure 19-Panel failure for different panel thicknesses.

\section{Discussion}

It is believed that the presented approach and parameter studies above are reasonably realistic, as long as the occurring insulation and connection temperatures remain low, so their neglected temperature dependency can be accepted. Nevertheless, these limitations should be improved. Firstly, forces or deformations on the screws and bolts can be studied by a detailed and temperature dependent FEM model of the connection itself, and subsequently, the resulting deformations or forces can be used in the simulation, as such following an approach similar to multi-scale modelling.

Secondly, as mentioned earlier, the approach has been verified internally (see also Feenstra et al., 2018), and partly with Eurocode design rules and an ISO fire curve. However, it is crucial to verify the approach with real fire experiments.

Then, the failure mode of the façade deforming such that gaps occur, as presented in section 3.5.2, was not found for the simulations, and consequently, and due to its complexity, the option to model these small gaps was not modelled systematically in the CFD simulations. Still, some tests were carried out by simply modelling a small gap at the start of a simulation. These tests showed the mesh size of the CFD fire model should be as small as the gap size, which led to high computational costs. The results suggested that the gaps did not affect the fire and the temperature at the façade interior significantly, but showed flames outside of the façade, as shown in Figure 22. These external flames may start the fire spreading in the façade structure itself via openings, cavities and corners. As these effects are not currently modelled, AST measurement points could be added at the outer side of the façade, and a realistic thermal resistance of the façade should be implemented to achieve realistic outside temperatures. This will also be usable to predict the consequences of the explosion after the failure of a panel. 

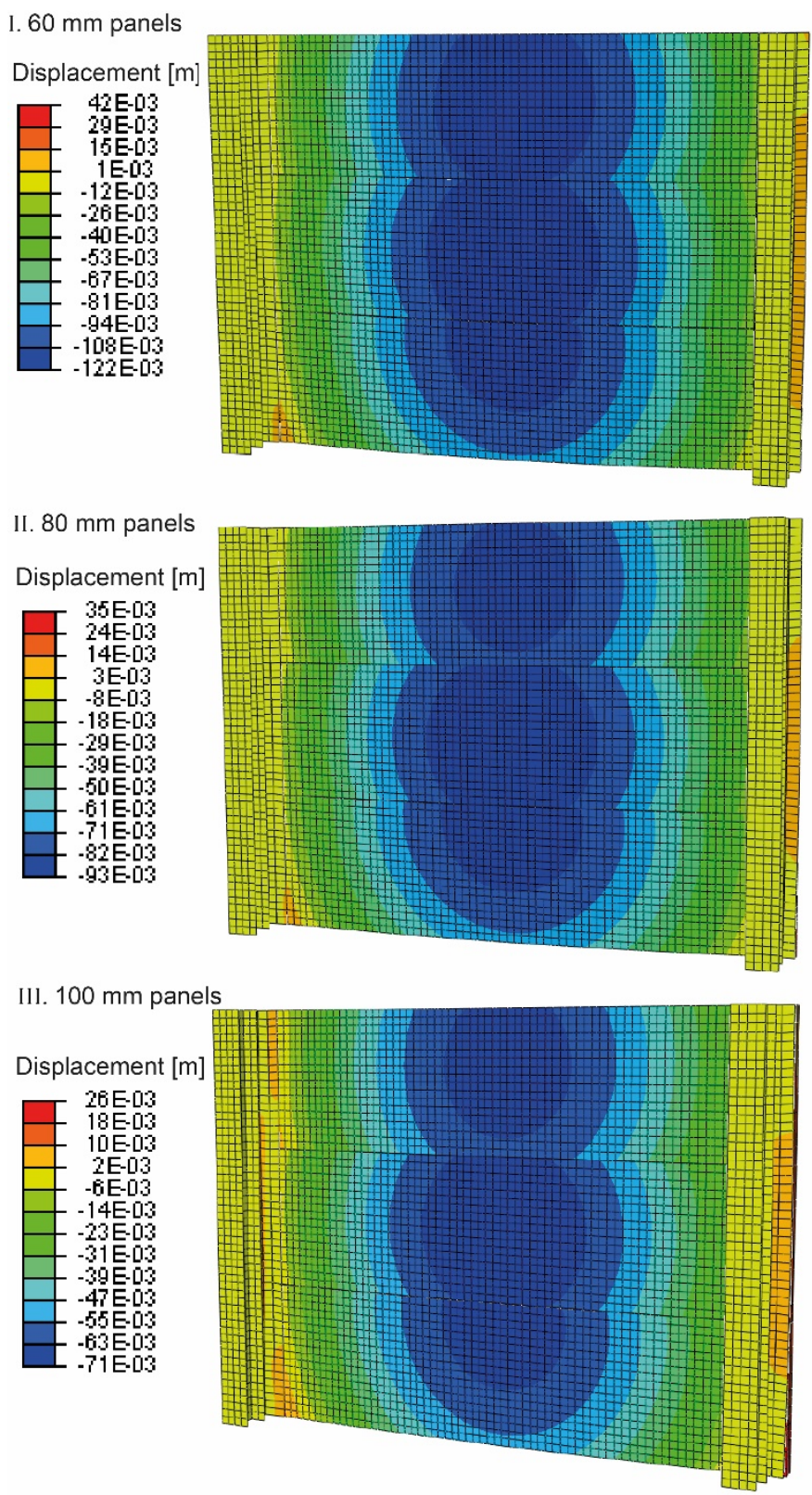

Figure 20 -Out-of-plane displacements at $t=35 \mathrm{~s}$ for different panel thicknesses.

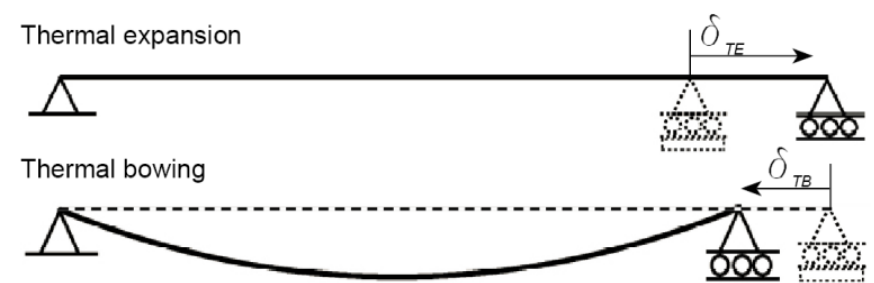

Figure 21 - Mechanics scheme visualising the opposite contributions of thermal expansion and thermal bowing to the displacement of the roller support.

Fourthly, the FEM models currently have a basic level of PIR core modelling, whereas in reality it is a complex material, especially when exposed to high temperatures. The PIR material starts to melt at around $450{ }^{\circ} \mathrm{C}$, and also encapsulates highly flammable gas, which escapes for high temperatures. Both aspects affect the thermal and structural behaviour of the sandwich panels.

Finally, high temperature creep, which starts at $400{ }^{\circ} \mathrm{C}$ for a steel structure, can be taken into account. Neglecting high temperature creep results in a stiffer structure with smaller deflections, but higher thermally induced stresses. 
However, it should be noted that for the simulations carried out here, having a fast heating rate, including creep will not change the outcomes significantly (Kodur \& Dwaikat, 2010).

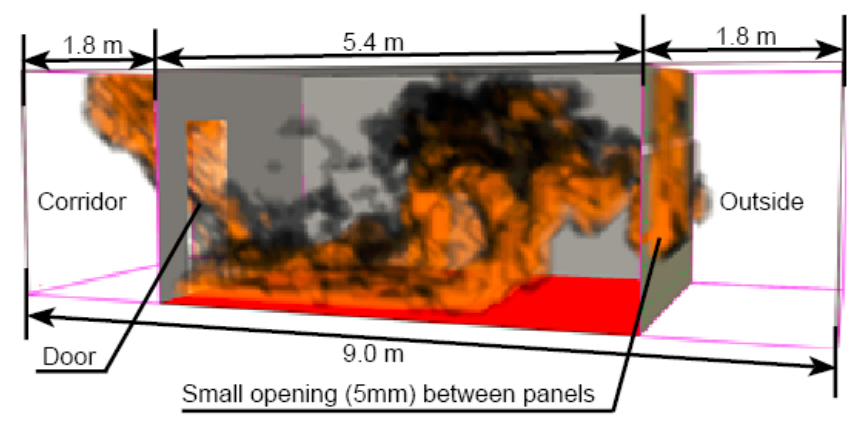

Figure 22 - Fire simulation after a $5 \mathrm{~mm}$ gap has been enforced between two façade panels. The outside flames may lead to fire spreading in the façade, especially via vertical cavities and when combustible materials are present.

\section{Conclusions}

This study has shown the feasibility of performing a two-way coupled fire-thermomechanical analysis for a façade system exposed to fire. Each component of the system was subject to one or more failure criteria, and their consequences were modelled. For this, FDS-2-Abaqus enabled an automated approach, with one or two-way coupled CFD-FEM analyses.

Inevitably, the detailed modelling of some aspects of the structure draws attention to other aspects that have not been modelled with the same level of detail because they are very complex. In this research, the sandwich panel insulation has been simplified significantly, e.g. linear elastic theory has been used in combination with a simple design code failure criterion for the panel, and partial failure has been neglected by removing the panel completely. Also, possible gaps have not been implemented as they would require a dramatically finer CFD mesh. Finally, the design code predictions for screw and bolt failure are known to be unable to cover all the complexities involved, and are based on temperature independent properties.

Still, it has been shown that via the implemented parametric setup, the influences of relevant variables can be investigated. Although experiments are definitely needed to verify the limited approach, as can be seen above, the possibility of parameter studies can save at least a number of real, complex, and costly experiments in the design phase.

Independent of the lack of detailed modelling for all components, the two-way coupled CFD-FEM analysis showed significance differences compared to the one-way coupled analysis, the latter with either the fire modelled by CFD or by the ISO-834 curve. For fire fighters, of importance is the explosion that occurs after the failure of a panel due to the large amount of oxygen that becomes available. For the integrity of the façade itself, the loss of a façade panel releases the out-of-plane restraint for the other panels, leading to earlier failure of the façade system as a whole. Finally, the predicted failure of two tiny but critical screws within 80 seconds can be compared to the 150 minute lasting sandwich panels in standard fire tests. Nothing is more convincing than this to encourage the study of complete systems with the interaction of components, rather than studying individual components in standard fire tests.

Despite increased complexity, data and computational costs, it is therefore recommended to perform two-way coupled CFD-FEM analyses if the resistance of façade systems under fire are studied.

\section{References}

Alos-Moya, J., Paya-Zaforteza, I., Garlock, M. E. M., Loma-Ossorio, E., Schiffner, D., \& Hospitaler, A. (2014). Analysis of a bridge failure due to fire using computational fluid dynamics and finite element models. Engineering Structures, $68,96-110$. 
Andreozzi, A., Bianco, N., Musto, M., \& Rotondo, G. (2014). Adiabatic surface temperature as thermal/structural parameter in fire modeling: Thermal analysis for different wall conductivities. Applied Thermal Engineering, 65(1-2), 422-432.

Banerjee, D., Hess, W., Olano, M., \& Terrill, J. (2009). Visualisation of structural behavior under fire. National Institute of Standards and Technology. NISTIR7619, Gaitersburg, USA.

Baum, H.R. (2011). Simulating fire effects on complex building structures. Mechanics Research Communications, 38(1), 1-11.

Beata, P.A., \& Jeffers, A.E. (2015). Spatial homogenization algorithm for bridging disparities in scale between the fire and solid domains. Fire Safety Journal, 76, 19-30.

Chen, L., Luo, C., Lua, J. (2011). FDS and abaqus coupling toolkit for fire simulation and thermal and mass flow prediction. Fire Safety Science, 10, 1465-1477.

De Boer, J.G.G.M. (2018). Automated two-way coupled CFD fire and thermomechanical FE analyses of a selfsupporting sandwich panel façade system, MSc-thesis, Eindhoven University of Technology, Department of the Built Environment, The Netherlands, https://pure.tue.nl/ws/portalfiles/portal/111297465/Boer_de_0778519.pdf

Duthinh, D., McGrattan, K., \& Khaskia, A. (2008). Recent advances in fire-structure analysis. Fire Safety Journal, 43(2), 161-167.

EN 14509:2013 (201306). Self-supporting double skin metal faced insulating panels - Factory made products Specifications. Brussels, Belgium: European Committee for Standardisation.

EN 1991-1-2 (2002). Eurocode 1: Actions on structures - Part 1-2: General actions - Actions on structures exposed to fire. Brussels, Belgium: European Committee for Standardisation.

EN 1993-1-2 (2005). Eurocode 3: Design of steel structures - Part 1-2: General rules - Structural fire design. Brussels, Belgium: European Committee for Standardisation.

EN 1993-1-3 (2006). Eurocode 3: Design of steel structures - Part 1-3: General rules - Supplementary rules for coldformed members and sheeting. Brussels, Belgium: European Committee for Standardisation.

EN 1993-1-8 (2005). Eurocode 3: Design of steel structures - Part 1-8: Design of joints. Brussels, Belgium: European Committee for Standardisation.

EN 1999-1-4 (2007). Eurocode 9: Design of aluminium structures - Part 1-4: Cold-formed structural sheeting. Brussels, Belgium: European Committee for Standardisation.

Feenstra, J. A., Hofmeyer, H., Van Herpen, R. A. P., \& Mahendran, M. (2018). Automated two-way of CFD fire simulations to thermomechanical FE analyses at the overall structural level. Fire Safety Journal, 96, 165-175.

Franssen, J. M. (2005). SAFIR: A thermal/structural program for modeling structures under fire. Engineering Journal, 42(3), 143-158.

Guillaume, E., Fateh, T., Schillinger, R., Chiva, R., \& Ukleja, S. (2018). Study of fire behaviour of facade mock-ups equipped with aluminium composite material-based claddings, using intermediate-scale test method. Fire and Materials, 42, 561-577.

Gunalan, S., \& Mahendran, M. (2013). Finite element modelling of load bearing cold-formed steel wall systems under fire conditions. Engineering Structures, 56, 1007-1027. 
Hu, X., Wang, D., \& Wang, S. (2013). Synergistic effects of expandable graphite and dimethyl methyl phosphonate on the mechanical properties, fire behaviour, and thermal stability of a polyisocyanurate-polyurethane foam. International Journal of Mining Science and Technology, 23(1), 13-20.

Hurley, M. J., Gottuk, D., Hall, J. R., Harada, K., Kuligowski, E., Puchovsky, M., ... Wieczorek, C. (2016). SFPE handbook of fire protection engineering, fifth edition. SFPE Handbook of Fire Protection Engineering, Fifth Edition.

ISO 834-1 (1999). Fire-resistance tests - Elements of building construction - Part 1: General requirements. Geneva, Switzerland: International Organization for Standardization.

ISO 898-1 (2013). Mechanical properties of fasteners made of carbon steel and alloy steel - Part 1: Bolts, screws and studs with specified property classes - Coarse thread and fine pitch thread. Switserland, Geneva: International Organization for Standardization.

Kirby, B. (1997). Large Scale Fire Tests: The British Steel European Collaborative Research Programme On The Bre 8storey Frame. Fire Safety Science, 5, 1129-1140.

Kodur, V. K. R., \& Dwaikat, M. M. S. (2010). Effect of high temperature creep on the fire response of restrained steel beams. Materials and Structures, 43(10), 1327-1341.

Kolarkar, P.N. (2011). Structural and Thermal Performance of Cold-formed Steel Stud Wall Systems under Fire Conditions, PhD-thesis, Queensland University of Technology.

Looyeh, M. R. E., Rados, K., \& Bettess, P. (2001). Thermochemical responses of sandwich panels to fire. Finite Elements in Analysis and Design, 37(11), 913-927.

Lou, G., Wang, C., Jiang, J., Jiang, Y., Wang, L., \& Li, G.Q. (2018). Experimental and numerical study on thermalstructural behavior of steel portal frames in real fires. Fire Safety Journal, 98, 48-62.

Luo, C., Chen, L., Lua, J., Liu, P. (2010). Abaqus fire interface simulator toolkit (AFIST) for coupled fire and structural response prediction. In: Proceedings AIAA/ASME/ASCE/AHS/ASC Structures, structural dynamics, and materials conference, April 12-15, 2010. Orlando, Florida, USA. Vol. 4, 3361-3380.

Maljaars, J., Soetens, F., \& Snijder, H. H. (2009). Local buckling of aluminium structures exposed to fire. Part 1: Tests. Thin-Walled Structures, 47(11), 1404-1417.

Maljaars, J., Soetens, F., \& Snijder, H. H. (2009a). Local buckling of aluminium structures exposed to fire. Part 1: Tests. Thin-Walled Structures, 47(11), 1404-1417.

Maljaars, J., Soetens, F., \& Snijder, H. H. (2009b). Local buckling of aluminium structures exposed to fire. Part 2: Finite element models. Thin-Walled Structures, 47(11), 1418-1428.

McGrattan, K., Hostikka, S., McDermott, R., Floyd, J., Weinschenk, C., \& Overholt, K. (2013). Fire dynamics simulator, technical reference guide. National Instutute of Standards and Technology, Gaithersburg, Maryland, USA, and VTT Technical Research Centre of Finland, NIST special publication 1018-3, Espoo, Finland (Vol. 3).

Modesti, M., Lorenzetti, A., Simioni, F., \& Checchin, M. (2001). Influence of different flame retardants on fire behaviour of modified PIR/PUR polymers. Polymer Degradation and Stability, 74(3), 475-479.

NIST (2005). National Institute of Standards and Technology (NIST). Federal building and fire safety investigation of the world trade center dissaster: Final report of the national construction safety team on the collapse of the world trade center towers (NIST NGSTAR1). Gaithersburg, MD, USA.

Prasad, K., \& Baum, H.R. (2005). Coupled fire dynamics and thermal response of complex building structures. Proceedings of the Combustion Institute, 30(2), 2255-2262. 
Pyl, L., Schueremans, L., Dierckx, W., \& Georgieva, I. (2012). Fire safety analysis of a 3D frame structure based on a full-scale fire test. Thin-Walled Structures, 61, 204-212.

Ren, A., Shi, J., \& Shi, W. (2007). Integration of fire simulation and structural analysis for safety evaluation of gymnasiums-With a case study of gymnasium for Olympic Games in 2008. Automation in Construction, 16(3), 277289.

Ryder, N. L., Sutula, J. A., Schemel, C. F., Hamer, A. J., \& Brunt, V. Van. (2004). Consequence modeling using the fire dynamics simulator. Journal of Hazardous Materials, 115(1-3 SPEC. ISS.), 149-154.

Sanad, A. M., Rotter, J. M., Usmani, A. S., \& O'Connor, M. A. (2000). Composite beams in large buildings under fire numerical modelling and structural behaviour. Fire Safety Journal, 35, 165-188.

Silva, J. C. G., Landesmann, A., \& Ribeiro, F. L. B. (2014). Performance-based analysis of cylindrical steel containment Vessels exposed to fire. Fire Safety Journal, 69, 126-135.

Silva, J. C. G., Landesmann, A., \& Ribeiro, F. L. B. (2016). Fire-thermomechanical interface model for performancebased analysis of structures exposed to fire. Fire Safety Journal, 83, 66-78.

Spinardi, G., Bisby, L., \& Torero, J. (2017). A Review of Sociological Issues in Fire Safety Regulation. Fire Technology, 53(3), 1011-1037.

Stirna, U., Beverte, I., Yakusin, V., \& Cabulis, U. (2011). Mechanical properties of rigid polyurethane foams at room and cryogenic temperatures. Journal of Cellular Plastics, 47(4), 337-355.

Tondini, N., Vassart, O., \& Franssen, J. (2012). Development of an Interface Between CFD and FE Software. 7th International Conference on Structures in Fire, June 6-8, ETH Zurich, Switzerland, 459-468.

Usmani, A. S., Rotter, J. M., Lamont, S., Sanad, A. M., \& Gillie, M. (2001). Fundamental principles of structural behaviour under thermal effects. Fire Safety Journal, 36(8), 721-744.

Wade, C.A., \& Clampett, J.C. (2000). Fire Performance of Exterior Claddings, BRANZ Report FCR 1, Building Research Association of New Zealand. Judgeford, New Zealand.

Wang, Y.C., Lennon, T., \& Moore, D. B. (1995). The behaviour of steel frames subject to fire. Journal of Constructional Steel Research, 35(3), 291-322.

Wang, Y.C., \& Foster, A. (2017). Experimental and numerical study of temperature developments in PIR core sandwich panels with joint. Fire Safety Journal, 90, 1-14.

Weghorst, R., Hauze, B., \& Guillaume, E. (2016). Determination of fire performance of ventilated facade systems on combustible insulation using LEPIR2. Extended applications approach based on multiscale tests. Proceedings of 14th international fire and engineering conference Interflam, vol 2, 1139-1149.

Welch, S., Miles, S., Kumar, S., Lemaire, T., \& Chan, A. (2008). FIRESTRUC - Integrating advanced three-dimensional modelling methodologies for predicting thermo-mechanical behaviour of steel and composite structures subjected to natural fires. Fire Safety Science, 9, 1315-1326.

White N., \& Delichatsios, M. (2015). Fire Hazards of Exterior Wall Assemblies Containing Combustible Components, Springer-Verlag New York, ISBN 978-1-4939-2897-2.

Wickström, U. (2008). Adiabatic surface temperature and the plate thermometer for calculating heat transfer and controlling fire resistance furnaces. Fire Safety Science, 9, 1227-1238. 
Wickström, U., Duthinh, D., \& McGrattan, K. (2007). Adiabatic surface temperature for calculating heat transfer to fire exposed structures. In: Proceedings $11^{\text {th }}$ international Interflam conference, September 3-5, 2007. London, England. Vol. 2, 943-953.

Yu, X., \& Jeffers, A.E. (2013). A comparison of subcycling algorithms for bridging disparities in temporal scale between the fire and solid domains. Fire Safety Journal, 59, 55-61.

Zhang, C., Choe, L., Gross, J., Ramesh, S., \& Bundy, M. (2017). Engineering Approach for Designing a Thermal Test of Real-Scale Steel Beam Exposed to Localized Fire. Fire Technology, 53(4), 1535-1554.

Zhang, C., Silva, J. G., Weinschenk, C., Kamikawa, D., \& Hasemi, Y. (2016). Simulation Methodology for Coupled FireStructure Analysis: Modeling Localized Fire Tests on a Steel Column. Fire Technology, 52(1), 239-262.

Zhang, C., Yu, H. X., Choe, L., Gross, J., \& Li, G. H. (2017). Simulating the fire-thermal-structural behavior in a localized fire test on a bare steel beam. Engineering Structures, 163, 61-70. 